\title{
Color Properties and Color Ascriptions: A Relationalist Manifesto
}

\author{
Jonathan Cohen*
}

Upon examination, I find only one of the reasons commonly produc'd for this opinion to be satisfactory, viz. that deriv'd from the variations of those impressions, even while the external object, to all appearance, continues the same. These variations depend upon several circumstances. Upon the different situations of our health: A man in a malady feels a disagreeable taste in meats, which before pleas'd him the most. Upon the different complexions and constitutions of men: That seems bitter to one, which is sweet to another. Upon the difference of their external situation and position: Colours reflected from the clouds change according to the distance of the clouds and according to the angle they make with the eye and luminous body. Fire also communicates the sensation of pleasure at one distance, and that of pain at another. Instances of this kind are very numerous and frequent.

- Hume, A Treatise of Human Nature, Book I, part iv, "Of The Modern Philosophy".

Are colors relational or non-relational properties of their bearers? Is red a property that is instantiated by all and only the objects with a certain intrinsic (/non-relational) nature? Or does an object with a particular intrinsic (/nonrelational) nature count as red only in virtue of standing in certain relations for example, only when it looks a certain way to a certain perceiver, or only in certain circumstances of observation? In this paper I shall argue for the view that color properties are relational (henceforth, relationalism), and against the view that colors are not relational (henceforth, anti- or non-relationalism).

Before I come to this, a caveat is in order. Relationalism is not, by itself, a theory of the nature of color (although it may be more easily reconciled with some theories of the nature of color than others). It is a theory about what sorts of properties colors are - namely, that they are relational properties; but it does not say which properties of that sort — which relational properties, in particular - colors are. As it happens, relationalism has been seen by its fans and foes (e.g., [McGinn, 1983], [Stroud, 2000]) as the most important support for the view that colors are dispositions to appear certain ways to subjects (this is a view sometimes ascribed to modern philosophers such as Galileo, Boyle, Newton, Locke, and defended by more recent writers such as [McGinn, 1983],

* Department of Philosophy, University of California, San Diego, 9500 Gilman Drive, La Jolla, CA 92093-0119, joncohen@aardvark.ucsd.edu 
[Peacocke, 1984], and [Johnston, 1992]); however, relationalism is compatible with non-dispositionalist accounts of color as well. ${ }^{1}$

The question of whether colors are relational puts substantive constraints on what counts as an adequate color ontology, but answering that question will leave plenty of room for disagreement about what colors are. In this sense, the relationalist view for which I shall argue in this paper might be construed as a framework for an ontology of color.

With this caveat in mind, I turn to the question of whether colors are relational.

\section{What is Color Relationalism?}

First, however, I must say something about how I am understanding that question.

A relationalist holds that colors are relational - in particular, that they are constituted in terms of some relation between (inter alia) objects and perceivers. Presumably, this view should be understood by way of contrast with the view that colors are non-relational properties of their bearers. Unfortunately, there is no uncontroversial account of the relational/non-relational distinction to which we can turn. On the other hand, I take it that we have a pre-theoretical grasp on the distinction that comes out in our agreement about paradigm cases: being a sister and being 50 meters to the left of a philosopher are relational properties, while being cubical and having a mass of $50 \mathrm{~kg}$ are non-relational. ${ }^{2}$ Moreover, we have a pre-theoretical grasp on what distinguishes relational from non-relational properties: roughly, a non-relational property of $x$ is a property that $x$ has (or

1 For example, another form of relationalism is the so-called "enactive" view of [Thompson et al., 1992] and [Thompson, 1995], which attempts to understand colors in terms of the varying (ecologically described) functions performed by the visual systems of different species of organisms. Yet another is the view of [McGinn, 1996] that colors are not the dispositions to look colored, but properties that supervene on those dispositions.

A further relational account is the functionalist view, defended by [Jackson and Pargetter, 1987], [Jackson, 1996], [Jackson, 1998], [McLaughlin, 2003], and [Cohen, 2003a], that colors are the properties that dispose their bearers to cause particular types of sensations in certain kinds of minds. Functionalism is in many respects closely related to dispositionalism, but the two views cannot be identified: functionalists say that colors are the properties in virtue of which things have their dispositions to look colored, not the dispositions themselves, while dispositionalists identify colors with the dispositions in question. Nor should functionalism be thought of as an anti-relational account of colors: functionalists think colors are not particular intrinsic (hence non-relational) structures, but the second-order properties of having some or other structures in virtue of which their bearers are related to observers in a certain way. Consequently, functionalists claim that colors are constituted in terms of relations to observers, and therefore, on the construal of relationalism elaborated below, should count as defenders of a relational view. For more on these themes, see [Cohen, 2003a].

${ }^{2}$ In saying that these paradigm examples of relational and non-relational properties express our pre-theoretical understanding of the distinction, I mean that we don't need a philosophical account of the relational/non-relational distinction to classify these properties as relational or non-relational; on the contrary, these classifications are data that any acceptable philosophical account of the distinction must respect. 
lacks) regardless of the relations $x$ bears to things other than $x .^{3}$

It is worth noting at this point that one sometimes finds in the literature (e.g., [Tye, 2000], 152) that the view that colors are relational is contrasted with the view that colors are intrinsic properties. Now, the antonym of 'relational' is obviously 'non-relational', rather than 'intrinsic', and this matters because it is controversial whether the relational/non-relational distinction coincides with the intrinsic/extrinsic distinction. Consequently, the main contrast of concern in this paper will be that between relational and non-relational views of color. However, there does seem to be a connection between the two distinctions that will be relevant. Namely, if an intrinsic property is characterized in a roughand-ready way as "a property that a thing has (or lacks) regardless of what may be going on outside itself" ([Yablo, 1999], 479), then intrinsic properties will also be non-relational. ${ }^{4}$ For $x$ cannot bear a relation to something other than $x$ (hence cannot exemplify a relational property) regardless of what may be going on outside itself: at a minimum, $x$ cannot bear a relation $R$ to $y$ (and hence cannot exemplify a relational property) unless $y$ exists. ${ }^{5}$ For this reason, we may find that claims about the intrinsicness of properties are germane to the debate over whether colors are relational.

To return to the main line of discussion, we can express the point of contention between relational and non-relational accounts of color in terms of the paradigm examples cataloged above: the question is whether being red is more like being the sister of $b$ (i.e., a relation that yields relational properties when

\footnotetext{
${ }^{3}$ Whether one thinks of this as a satisfactory analysis of non-relationality or not depends on whether one thinks we have a prior satisfactory understanding of relations, and of the individuation of particulars (inter alia). I've called the paraphrase in the main text a "pretheoretical grasp" rather than an analysis just so as to avoid begging these questions.

${ }^{4}$ As Yablo notes immediately, this characterization is obviously circular, in that the variations we are allowed to make when testing a property for intrinsicness have to be variations that are extrinsic to the instance of our test property (lest all properties turn out to be extrinsic). However, the circularity of the characterization does not show that it is false (or, as Yablo argues, incapable of inspiring a non-circular account along the same lines).

${ }^{5}$ Brian Weatherson has pointed out that there can be counterexamples in cases where the relational property in question is constituted in terms of a relation that, as it were, relates a thing to one of its proper parts. I propose to stipulate such cases out of consideration, since they seem not to overlap with the cases I'll be wanting to discuss in the present debate about color properties.

Let me emphasize also that I intend the point in the main text to hold for any account of the intrinsic/extrinsic and relational/non-relational distinctions that attempts to cash out the rough and ready characterizations I have appealed to. In particular, all the accounts of those distinctions that I have seen in the literature can be understood in this way, so a proponent of any of these accounts should agree with the point I am making. (The point may not hold for those who take the intrinsic/extrinsic distinction to be identical with the essential/accidental distinction or the real/unreal distinction; but I take it that these uses of 'intrinsic' and 'extrinsic' are confused, and therefore I shall put them aside.)

Finally, note also that my claim about relational properties is not in conflict with the view, defended in [Langton and Lewis, 1998], that some relations are intrinsic. According to them, a relation $R$ is intrinsic "iff it never can differ between duplicate pairs" (343). But the relational property of bearing $R$ to something is, on the understanding adopted above, a property of a single individual, not a pair; whether an individual $x$ can exemplify this relational property depends on things other than $x$, and consequently the (arbitrary) relational property is not intrinsic.
} 
relevant parameters are filled in) or being cubical (i.e., a non-relational property for which there are no parameters in need of filling). And in view of our pretheoretical grasp of the relational/non-relational distinction, we may express that question in this way. Suppose $x$ is something red; then, as we modify things other than $x$, and thereby modify the relations $x$ bears to other things, will $x$ (necessarily) continue to be red? If so, then being red is non-relational; if not, it is relational. ${ }^{6}$

This way of marking the relational/non-relational distinction, it seems to me, crystallizes one of the key issues that divides accounts of color.

On the non-relational side of the distinction are those who understand colors as objective and mind- or perceiver-independent; in particular, they insist that colors are not constituted in terms of relations to subjects or minds, so their view predicts that molecular duplicates of red things will be red even in worlds where there are no minds (/perceivers). A typical account of this sort is one that takes colors to be physical properties - usually some kind of reflectance property of surfaces, transmittance property of transparent surfaces and volumes, emittance property of luminous sources, or some combination of these. $^{7}$ Non-relational theories of color have become increasingly popular in recent years; versions of them are defended by [Armstrong, 1968], chapter 12, [Hilbert, 1987], [Byrne and Hilbert, 1997a], [Ross, 1999], and [Tye, 2000]. ${ }^{8}$

\footnotetext{
${ }^{6}$ The corresponding position in metaethics is generally discussed under the label 'relativism' rather than 'relationalism', and some writers (e.g., [Spackman, 2002], [Jakab and McLaughlin, 2003]) have followed suit in discussions of color. In my view, this terminological choice lays the emphasis in the wrong place. I would have thought that what is relativized, in the first instance, are the linguistically expressed color ascriptions; but this relativity is a linguistic reflex of an underlying metaphysical point (that colors are constituted in terms of relations) that is my main quarry. Accordingly, I prefer 'relationalism' since it appropriately draws attention to the metaphysics rather than the linguistic expressions.

${ }^{7}$ However, other versions of non-relational theories of color are possible as well; for example, one might hold that colors are non-relational but non-physical (whatever that comes to), or non-relational but unanalyzable (a fortiori, not susceptible of analysis in terms of physical kinds). That said, the prevailing non-relational accounts of colors take them to be physical, and this has encouraged writers to discuss these accounts under a variety of seemingly non-equivalent labels, including 'color objectivism', 'color physicalism', and (adverting to the distinction among primary and secondary qualities of matter adumbrated by modern philosophers such as Galileo, Boyle, and Locke) 'primary quality theory of color'. Much as I am loath to add to this terminological jungle by proposing to sort theories of color by the relational/non-relational distinction, it seems to me that this criterion allows for a clearer presentation of (at least some of) the issues that divide the theories.

8 A difficulty with the characterization I am proposing is that some of the accounts listed here (under the heading 'non-relational accounts') construe colors as relational properties after all — viz., they construe colors in terms of relations between objects and light. However, these accounts still insist that colors are not constituted in terms of relations to subjects. The best way to mark the distinction at issue, therefore, would be in terms of whether colors are understood in terms of relations to subjects (rather than in terms of whether colors are understood in terms of relations per se). (For the same reason, I won't count it a victory for relationalism about colors if it turns out that all properties are constituted in terms of relations; for, even if this view is right, we can still formulate the debate about color relationalism by asking whether the relations in terms of which color properties are constituted happen to be relations to subjects.) However, I'll put this qualification aside, and instead resort to the simpler contrast between relational and non-relational accounts, in the interest
} 
On the other side, there are views according to which colors are constituted in terms of relations between objects and subjects (and possibly other parameters, such as viewing conditions). On these views, molecular duplicates of red things could fail to be red in worlds where features not preserved by the molecular duplication are allowed to vary. ${ }^{9}$ One standard relational account, henceforth color dispositionalism, holds that colors are dispositions to cause certain sensations in certain kinds of minds; for example, on one version of this theory, red is the disposition to look red to normal observers. I think it is safe to say that dispositionalism is the received view about color ontology in philosophy; as mentioned above, versions of it have been ascribed (controversially) to a number of modern philosophers, and many more recent writers have defended the view as well (but see note 1 ). ${ }^{10}$

So much by way of defining terms. The more interesting question, of course, is why anyone might believe that colors are relational.

\section{From Perceptual Variation to Relationalism: The Master Argument}

Perhaps the most prominent argument for the relationality of color is based on consideration of wide interspecies, interpersonal, and intrapersonal variations

\footnotetext{
of expository convenience.

Notice that an exactly analogous complication arises in the more standard formulation of the distinction between these theories in terms of whether colors are construed as dispositions. For while accounts in the Armstrong-Hilbert tradition deny that colors are dispositions to affect perceivers, they construe colors as (roughly) dispositions to affect light in certain ways. Here too, both sorts of theories understand colors as dispositions of some sort, but they differ over whether the relevant dispositions crucially involve subjects. And here, too, writers have tended to set this complication aside for ease of exposition.

${ }^{9}$ This does not commit the relationalist to the view that nothing is red in a world where there are no minds, because a relationalist can unpack the colors in terms of a dispositional relation (or some other relation that would be expressed in terms of a subjunctive conditional). On such a view, $x$ can be red in $w$ (where there are no minds) if $x$ would be appropriately related to the minds in $w$, assuming there were any. (This is also not to say that relationalists must take this line; for example, arguably Locke did not intend his relationalism to be understood in terms of subjunctive conditionals (see [Rickless, 1997], 307ff).)

${ }^{10}$ Another view that should be mentioned in this geography is a hybrid position defended by Shoemaker (see lecture III of his Royce Lectures [Shoemaker, 1994b] and [Shoemaker, 1994a], and a slightly modified, dispositional version of the view in [Shoemaker, 2000b] and [Shoemaker, 2000a]; see also [Thau, 2002]). Shoemaker is sympathetic (because of considerations about perceptual variation very similar to those I invoke in $\S 2$ ) to the view that our experience of colors represents relational properties that are constituted in terms of relations to observers. However, he insists (e.g., [Shoemaker, 1994b], 254ff) that these relational properties are not identical to the colors. Of course, if he allowed this identification, Shoemaker would be defending a species of relationalism about color. Instead, he claims that our color experience represents both the (non-relational) color property and the corresponding relational property - he calls the latter a 'phenomenal property' or an 'appearance property'. In private correspondence, Shoemaker tells me he favors this hybrid view over relationalism for reasons similar to those I consider (and respond to) in $\S 4$. (He also indicates that he is currently rethinking his commitment to the idea that appearance properties are represented in experience.)
} 
with respect to color perception. ${ }^{11}$ This argument (henceforth, the argument from perceptual variation), which can certainly be found in the writings of modern philosophers such as Galileo, Locke, and Hume, is also propounded in more recent relationalist works including [Bennett, 1968] and [McGinn, 1983]. In rough outline, this argument works in two stages: in the first, the relationalist points to the wide variety of perceptual effects (in respect of color) of a single stimulus; in the second, she alleges that there is no independent and well-motivated reason for thinking that just one of the variants is veridical (at the expense of the others). But if there is no singling out a single one of the variants at the expense of the others, then we must reconcile the variants; and the way to reconcile apparently incompatible variants is to view them as the result of relativizing colors to different values of certain parameters, which is just to admit that colors are relations between objects and those parameters.

I'll clarify this schematic overview of the argument from perceptual variation by providing a concrete instance of the argument in $\S 2.1$.

\subsection{Perceptual Variation: A Concrete Case}

As a single concrete case of perceptual variation with respect to color that will serve as the first stage of the argument, consider figure 1 (an achromatic example) and figure 2 (a chromatic example, in case you are looking at a chromatically colored copy of this paper). ${ }^{12}$

In figure 1, the two central gray squares are intrinsically (hence nonrelationally) qualitatively identical, so let us pretend that we have a single gray square, placed against two different backgrounds (this pretense is innocuous: the effect can be reproduced with a single gray square against two backgrounds, as you can convince yourself with the aid of scissors and glue). But most people report that the central gray square looks different in respect of color depending on the background against which it is placed - in particular, they report that the central square looks darker when placed against a light background (as in the left half of figure 1) than when placed against a dark background (as in the right half of figure 1). We have, then, a variation in perceptual effects (in respect of color) of a single object (the gray square).

Similarly, in figure 2, the two central strips are intrinsically (hence nonrelationally) qualitatively identical, so we can pretend that there is just one strip, placed against two backgrounds. The strip looks noticeably different in respect of color depending on the background against which it is placed. Once again, there is a variation in perceptual effects (in respect of color) of a single object (the central strip). Of course, this is not yet a very wide amount

\footnotetext{
${ }^{11}$ In this section I shall focus on only one instance of the argument; I shall apply the argument more widely in $\S 3$.

12 Readers of achromatic copies should consult [Hurvich, 1981], chapter 13, and [Albers, 1963], chapter VI for chromatic examples. (Among the most compelling examples in [Albers, 1963] are Studies VI-2.1, VI-3.1, VI-3.2, and VI-4.2.) I have collected these, together with a few other examples, at http://aardvark.ucsd.edu/ joncohen/color/albers_examples.html. In any case, my argument is not limited to achromatic examples, even if your copy of the paper is.
} 
Figure 1: The two center gray squares have equal reflectances, but the one against the white background appears darker than the one against the black background.

of variation - so far I have provided only two different variants. But I can generate more variants easily, as in figure 3. (The set of perceptual variants can be expanded even more widely by the same method; I'll stop here, as I take it the general point is clear enough by now.)

Now comes the second stage of the argument, in which it is argued that there is no principled way of settling on one among the variants adduced at the first stage as the veridical representation of the true color of the object. Consider figure 3 once again; the identical gray central patch has a variety of perceptual effects, depending on the background against which it is placed. Suppose, for reductio, that color is a non-relational property. If so, then the central gray patch has a single color, irrespective of the background against which it is placed. It follows that at most one of the perceptual effects can veridically represent the color of the patch. But which one, and why? Notice that the question here is intended metaphysically, rather than epistemically: it is not 'how do ordinary perceivers know which of the varying perceptual effects veridically represents the color of the patch?', but 'what makes it the case that one of the varying perceptual effects (as opposed to the others) veridically represents the color of the patch?'.

The relationalist is moved by the difficulty of answering this question. It is, she thinks, difficult to imagine a well-motivated, principled, and non-questionbegging criterion that makes one of these perceptual effects veridical at the expense of the others. But if there is no principled criterion that favors one of the perceptual effects rather than the others, this gives us reason for rejecting the initial supposition that colors are non-relational in favor of the view that colors are relational. In particular, the present case suggests that colors are constituted in terms of a relation to background configurations (or, more generally, to objects seen simultaneously). For if colors were so constituted, we 
Figure 2: The two center strips are qualitatively identical, but there is an obvious difference in their color appearance.

Figure 3: The center gray patches have equal reflectances, but they have different perceptual effects depending on the background against which they are placed.

could easily accommodate the observed range of perceptual variation: we could say that the central patch in figure 1 exemplifies one color when placed against the light background on the left half of the figure, and a different color when placed against the dark background on the right half of the figure (mutatis mutandis for figures 2 and 3 ). Thus, the second stage of the argument involves the thought that, in order to accommodate the observed perceptual variation, the non-relationalist is forced to make ad hoc stipulations, while the relationalist is not. Accordingly, as ad hoc stipulation should be avoided when possible, we should favor relationalism.

Before proceeding to consider objections to the argument from perceptual variation, I want to emphasize that it is not intended as a knock-down deductive argument, but as some sort of inference to the best explanation. I have not attempted to show that there is any inconsistency in the thought that one perceptual variant is veridical at the expense of the others, but only that it's 
hard to see what (besides ad hoc stipulation) could make this the case. Likewise, in later generalizations of the argument, I will be arguing for relationalism by showing that non-relationalist responses to cases of perceptual variation require unprincipled and unmotivated stipulations of various sorts. In contrast, I claim, embracing relationalism allows us to avoid such stipulations. The argument I'm running, then, depends on the general principle that we should take measures to avoid ad hoc stipulation when possible - a principle I take to be well-advised, despite its not conferring demonstrative force. Of course, to accept this general principle is not to say that stipulation is never justifiable. It is to say only that we should avoid stipulation unless we are forced to it by independent and unavoidable pressures, a fortiori, that we should avoid it when - as in the present case - there are available non-stipulative alternatives.

It is worth considering, at this point, a number of possible objections to the argument given so far.

\subsection{Reduction Tubes}

A first objection against the argument from perceptual variation is the accusation that, contrary to what is asserted in the argument's second stage, there are well-motivated and independent reasons for settling on one of the perceptual variants as veridically representing (to the exclusion of other variants) the color of objects. Just confining ourselves to the kinds of variations we have been considering, the objector might insist that the real color of an object can only be perceived in a case where there are no simultaneous contrast effects — viz., in a case where the test object is viewed through a reduction tube that blocks out all other objects. Whether this choice is counted a choice of one of the variants (the variant in which there is no background at all) or a choice to reject all the variants in favor of a variant-free condition (the condition involving no background), the thought would be that this choice is principled, and that making it eliminates the troublesome perceptual variation. ${ }^{13}$

Unfortunately, this move seems to have a number of untoward consequences. First, it will follow that surfaces in the vast majority of ecologically valid settings will not look to the vast majority of ecologically valid observers to have the colors they in fact have, insofar as contrast effects are ubiquitous in ordinary color perception. Second, (as a limiting case of the first problem) a specification relying on the use of reduction tubes will have the consequence that nothing will ever have any of the contrast colors. Contrast colors are colors whose appearance depends essentially on contrast effects - colors that cannot appear in the absence of contrast. Contrast colors include many we encounter everyday (outside the psychophysics laboratory), such as brown, olive, pure white, and pure black. That these colors disappear when contrast is eliminated is

\footnotetext{
${ }^{13}$ Again, the discussion here is limited to perceptual variation with respect to contrast effects, even though there are many other dimensions of variation in terms of which the points discussed here can be made. See [Hardin, 1988] and $\S 3$ below on the particular proposals corresponding to different dimensions of perceptual variation, and for some reasons for thinking these proposals are unacceptable.
} 
a striking fact: subjects are often surprised that brown objects, when viewed through a reduction tube, appear either orange or yellow (cf. [Hardin, 1988], 70). Similarly, black objects shown on an otherwise colored television screen appear much darker than the turned-off television screen, even though the relevant local region of the screen is illuminated in the same way in both cases. Thus, if we insist that the true colors of objects are revealed only in viewing situations where contrast effects are precluded by the use of reduction tubes, we are forced to the counterintuitive consequence that, necessarily, nothing is brown, olive, pure black, or pure white. ${ }^{14}$ All this is to say we have made no progress on the problem of delimiting the range of perceptual variation; as shown by its counterintuitive consequences, the current proposal of eschewing backgrounds altogether, just as much as the choice of any particular background, amounts to an ad hoc stipulation. But if so, then the present response to the argument from perceptual variation does not (contrary to its advertised aims) offer us a way to avoid both perceptual variation and stipulation, and therefore is ineffective as a response to the argument from perceptual variation.

\subsection{Color Constancy}

A second objection to the argument from perceptual variation is based on an appeal to color constancy. ${ }^{15}$ Suppose a subject visually perceives the scene depicted in figure 4 - i.e., a coffee cup on a table, partially in direct sunlight and partially in shadow. ${ }^{16}$ Clearly the regions of the coffee cup (and the table) that are in direct sunlight are perceptually distinguishable for the subject from the (qualitatively identical) contiguous regions of the coffee cup (and the table) that are in the shadow, which is just to say that there is perceptual variation in respect of color for the qualitatively identical regions of the coffee cup. The subject will normally judge, however, that these perceptually distinguishable regions are of the same color - despite the perceptual variation, she will ordinarily judge that the two adjacent regions have one color rather than two. But, the objector continues, that judgment suggests that at most one of the two perceptual variants is a veridical representation of the shared color of the regions (even if we do not know which). And if we are prepared to say this about the perceptual variation in figure 4, why not think of the perceptual variation in figures 1-3 along the same lines? Why not suppose that, in these cases as well,

\footnotetext{
${ }^{14} \mathrm{~A}$ third line of objection is that, far from eliminating perceptual variation, the appeal to reduction tubes introduces further dimensions of perceptual variation, this time due to the variety of possible reduction tubes: the way a given patch looks in respect of color will vary substantially as a function of the materials and surface characteristics of the interior of the reduction tube through which it is viewed. I am not aware of any systematic psychophysical investigations of these effects.

${ }^{15}$ The arguments of this section are presented (and defended) in more detail in [Cohen, 2003b].

${ }^{16}$ It will be important here that the subject is visually perceiving a coffee cup, not a photograph of the coffee cup (notwithstanding the arguments of [Walton, 1984], I take it that when a subject sees a photograph of $x$, she does not ordinarily see $x$ as well; see [Cohen and Meskin, 2004]). I am using figure 4 to depict the stimulus - I am not using it as the stimulus.
} 
Figure 4: Partially sunlit coffee cup.

there is a fact of the matter about which (if any) of the perceptual variants veridically represents the true color of the test patch (even if we do not know which)?

By way of responding, I want to point out the objection turns crucially on having a partial view of the data about subject judgments in cases of color constancy. It is true that subjects will judge (when asked one way) that the adjacent regions have one color rather than two. On the other hand, the regions are obviously discriminable, and it is hard to say how they are discriminable except in respect of something like their color, which suggests that there is some important sense in which subjects will judge that the two regions are not alike in color (this second sort of judgment has been studied quantitatively by [Arend and Reeves, 1986]; cf. [Arend et al., 1991], [Troost and deWeert, 1991], [Cornelissen and Brenner, 1995], and [Bäuml, 1999]). So it looks as if the neutral thing to say is that subjects in color constancy experiments actually make two different judgments: they judge not only that the two regions of interest are (in some sense) alike in color, and also that the two regions are (in some sense) not alike in color. Now, it is not obvious how we should ultimately make sense of these apparently conflicting judgments. However, I submit, we should not respond to the situation by refusing to acknowledge that there is a perfectly good sense in which the adjacent patches are judged not to share a color. But that is just what the present objection amounts to - the point of the objection is that, despite the perceptual variation with respect to the adjacent regions, the judgment that the two share a color requires us to favor at most one of the variants at the expense of the other. This insistence seems unmotivated, how- 
ever, when considered in light of the simultaneously offered judgment that the two regions fail to share a color. The point, then, is that the present objection suggests that at most one variant in color constancy cases is veridical only if we take a selective view of the data.

On the other hand, there are ways of understanding subject judgments in color constancy experiments that (i) respect the full range of data, and (ii) do not require that at most one perceptual variant is veridical. Suppose, for example, that we understand the judgment that the adjacent regions share a color as answering this question: would region $R_{1}$ (presented under illumination $I_{1}$ ) share a color appearance with region $R_{2}$ (presented under illumination $I_{2}$ ) if, contrary to fact, both regions were presented under the same illumination - namely, both under $I_{1}$ or both under $I_{2}$ ? On this construal, the subject's judgment is not a judgment to the effect that the regions are occurrently manifesting a common color, but rather to the effect that the regions share a color that one of them is not occurrently manifesting. In particular, the judgment is that, although the sunlit region looks different (in respect of color) from the region in shadow, the two regions would look the same (in respect of color) were they both viewed under sunlight. (Of course, the two regions also share another color - namely, the color that either of them would exhibit in shadow but that only the currently shadowed region currently manifests.) This understanding still leaves room for accepting the judgment that the contiguous regions fail to share a color in some other sense: namely, we can understand this just as the judgment that the adjacent regions are unlike in the colors that they are occurrently manifesting. Thus, the present construal provides an account of subject judgments in color constancy experiments that (unlike the construal considered above) respects the full range of data. And now we may notice that, on the present construal, the subject's judgment gives no reason for believing that (as alleged) at most one of the perceptual variants is a veridical representation of the colors of objects. For, as noted, not only do the regions share the color that the sunlit region is currently manifesting, but they also share the color that the shadowed region is currently manifesting. That is to say, the regions share both of the colors represented by the perceptual variants; consequently, the judgment that they share a color in no way impugns the veridicality of either (currently manifested) perceptual variant.

The upshot of this discussion, then, is that subject judgments in color constancy cases do not, by themselves, give us any reason to believe that one variant in such cases is veridical (at the expense of the other); this result only follows given a certain understanding of the judgments in question, and in particular an understanding that is hard to reconcile with the full range of data about the cases. But if the phenomenon of color constancy fails to establish that at most one of the perceptual variants is veridical in the case now under consideration, then analogizing the cases involving figures $1-3$ to a case of color constancy won't rebut the argument from perceptual variation involving figures $1-3$. For this reason, I take it that the argument from perceptual variation withstands considerations about color constancy. 


\subsection{Is Every Property Relational?}

A third objection against the argument from perceptual variation that has been leveled by a number of authors alleges that that argument cannot be sound because it would also lead to the absurd conclusion that paradigm non-relational properties are relational. ${ }^{17}$ For example, Stroud writes that,

What colour you see when you see an object on a particular occasion does, of course, depend on the condition you are in and the circumstances in which you find yourself .... But that is true of the perception of all properties. Whether you get a perception of something ovoid from an ovoid object or a perception of an elephant from an elephant equally depends on your current state and the perceptual conditions. Alleged facts of "perceptual relativity" do not support a distinction between colours and certain "primary" or "real" properties which objects are said to have on their own, independently of all human perception ([Stroud, 2000], 174).

The thought here seems to be that perceptual variation cannot, by itself, show colors or any other properties are relational, insofar as there is perceptual variation with respect to at least some properties that are uncontroversially nonrelational (Stroud's examples of these are being ovoid and being an elephant). ${ }^{18}$

But this objection misses the force of the argument from perceptual variation that I have been rehearsing; in particular, it ignores the second stage of the argument, which breaks the analogy between color properties and paradigm non-relational properties. That is, the relationalist's argument is not merely that there is variation in color perception, but that, unlike the case of ovoid and elephant perception, there is no well-motivated, independent, and nonarbitrary criterion that makes one of the variants correct at the expense of the others. That is, while ovoid objects can look round and elephants can look like hippopotami under certain circumstances, we have criteria for ovoidness and elephantness (geometric and biological) that are independent of the way things look; with these criteria in hand, we have reason to say that the way objects look in such circumstances is not a definitive guide to whether they are ovoids or elephants. In stark contrast to these cases, we lack (non-stipulative) perception-independent criteria for the colors of things; therefore, unlike the case of perceptual variation with respect to being ovoid or being an elephant, the case of perceptual variation with respect to color is unresolvable without ad hoc stipulation. The reason that perceptual variation supports relationalism about color is that here it looks like relationalism is the only way to avoid ad

\footnotetext{
${ }^{17}$ This line of thought perhaps has its roots in Berkeley's complaint that Locke's secondary quality account of color is no more or less acceptable as an account of color than as an account of, say, shape.

${ }^{18}$ In fact, it is not at all uncontroversial that being an elephant is non-relational. Standard accounts of the metaphysics of species in terms of interbreeding (e.g., Mayr's biological species concept [Mayr, 1963]) would make the property being an elephant relational (see also [Hull, 1978], [Sober, 1984]). But Stroud's point, I take it, is that being an elephant is uncontroversially not constituted in terms of a relation to human perceivers. Cf. note 8 .
} 
hoc stipulation. In contrast, there are other ways - geometric and biological ways - to avoid ad hoc stipulation in the cases of perceptual variation with respect to being ovoid or being an elephant. That is why the argument from perceptual variation is a plausible argument for relationalism about being red, but not a plausible argument for relationalism about being ovoid or being an elephant. ${ }^{19}$

\section{The Master Argument In Action}

In $\S 2$ I presented the general form of the argument from perceptual variation to the conclusion that colors are relational properties, gave one concrete instance of that argument (that concerning simultaneous color contrast), and responded to a number of objections. At this point I want to extend the pattern of argument examined so far to a number of independent factors. In each case, I shall argue that there is a wide and ineliminable range of perceptual variation (with respect to color) as we modify the factor in question, and (relying on the pretheoretical grasp of the relational/non-relational distinction discussed in $\S 1$ ) therefore that the color of $x$ is a relation between (inter alia) $x$ and that factor. I'll organize the factors I consider under three headings: inter-species differences (§3.1), interpersonal differences (§3.2), and intrapersonal differences (§3.3).

\subsection{Inter-species Differences}

Pigeon visual systems are tetrachromatic - they use four (functionally individuated) channels to encode color information, and therefore an arbitrary color

\footnotetext{
19 Objection: Given the metaphysical (rather than epistemic) formulation of the issue, what matters is that there is a natural essence of elephanthood that can serve as a nonstipulative standard by which to adjudicate cases of perceptual variation; it doesn't matter at all whether we know (or anyone else knows) of the essence in question. But now why not suppose that there is a natural essence of color properties that could serve as a principled, non-stipulative standard by which to adjudicate cases of perceptual variation with respect to color? Admittedly, we don't have any idea what that essence might be; but why should we think there isn't an (unknown) essence even so?

Response: While there are some properties (e.g., perhaps being an elephant) that plausibly have natural essences, there are others (e.g., perhaps being humorous) that plausibly do not: it's hard to imagine that there is a mind-independent feature of joke $j$ that could vindicate my judgment that $j$ is humorous over your judgment that it is not. Why suppose, then, that color properties should be assimilated to properties of the former sort rather than the latter?

One reason for favoring the opposite choice is inductive: the history of unsuccessful systematic attempts to adumbrate the essences of color properties should itself cast some doubt on the enterprise. A second defeasible reason comes from attention to our own naïve inductive behavior. On the one hand, even novices ignorant about biological essences are inclined to make inductive projections to new instances of being an elephant (e.g., about surface behavior, form and causal profile) that are hard to explain without supposing that they are committed to the existence of a shared, mind-independent, constitutive ground of the property. In contrast, we are much less willing to make such inductive projections to new samples of both being humorous and being red, except where these inductions depend crucially on the way that the samples affect us. This suggests that we are not committed to (indeed, we are doubtful of) the existence of a shared mind-independent constitutive ground that could serve as an essence of these properties. (Cf. [Cohen, 2004] for a fuller discussion of these issues.)
} 
can be perceptually matched for a pigeon by a linear combination of four appropriately chosen primaries. ${ }^{20}$ In contrast, normal human visual systems are trichromatic - they use three (functionally individuated) channels to encode color information, and therefore an arbitrary color can be perceptually matched for a human being by a linear combination of three appropriately chosen primaries. Because of this difference, there are pairs of surfaces that are perceptual matches for human visual systems but not for pigeon visual systems. This entails that there is a difference between the way at least one surface of the pair looks to pigeon visual systems and the way it looks to human visual systems.

Which of these perceptual variants veridically represents the color of that surface? The four choices in logical space are these: (i) confine our attention to human visual systems, declaring that how things look to pigeon (and other) visual systems is irrelevant to the colors of objects; (ii) defer to the pigeons, holding that the way things look to them determines the true colors of objects; (iii) declare that neither we nor the pigeons are the true arbiters of color, and instead select a different standard; (iv) adopt the ecumenical policy that both sorts of visual systems are right, and that one and the same object can have more than one color property. Considered by itself, option (i) seems objectionably chauvinistic, while, considered by themselves, (ii) and (iii) seem unduly modest. This is not to say that the chauvinism following upon (i) (or the modesty following upon (ii) or (iii)) is incoherent, but only that these choices are revisionist with respect to quite a lot of ordinary and scientific talk about color (for example, just the sorts of apparently coherent questions about what colors pigeons see I'm asking here). I take it that some such revision would be warranted if there were hidden color-essences; however, for reasons discussed in note 19, it seems unreasonable to hold out hope for this outcome. But in the absence of color-essences, the revisionism in question will seem stipulative and unmotivated. I contend that we should avoid the stipulative revisionism unless we are forced to it.

However, now we should realize that we are not forced to it: option (iv) remains as a possible contender. Indeed, I find option (iv) extremely plausible, and suggest adopting it: we should construe colors as constituted in terms of relations to (inter alia) kinds of visual systems, and accept that if $x$ looks green to a visual system, $x$ is green for that visual system. ${ }^{21}$ It is a consequence of this relational construal that one and the same object can be simultaneously green for your visual system and not green for the visual system of the pigeon on your window ledge. ${ }^{22}$

\footnotetext{
${ }^{20}$ There is some dispute about whether pigeons have tetrachromatic or pentachromatic visual systems ([Thompson, 1995], 145-146), but all that will matter for the purposes to which I'll be putting pigeons is that the dimensionality and receptoral structure of their visual system is different from those of typical human beings. This claim is uncontroversial whether pigeons turn out to be tetrachromats or pentachromats.

21 For the record, accepting this material conditional does not require identifying the properties looks green to $S$ and is green for $S$. Compare: it is true that if $x$ is a sister, then $x$ is female, but it does not follow that the properties being a sister and being female are identical.

${ }^{22}$ Some non-relationalists have also accepted this last conclusion. For example, [Byrne and Hilbert, 2003] argue that colors are (not spectral reflectances, but) reflectance
} 


\subsection{Interpersonal Differences: Between-Subject Variations}

In section 3.1 I applied the master argument to variations in color perception between members of different species (across visual system types). Now I want to apply exactly the same argument form to variations in color perception between members of a single species (who share a visual system type); in particular, I shall focus attention on perceptual variation between human beings.

First, within our species there are a non-negligible number of anomalous trichromats, dichromats (both protanopes and deuteranopes), and (much more rarely) monochromats, achromatopes, and (possibly) some tetrachromats. ${ }^{23}$ Moreover, even within each of these functional classes, there are significant differences in the numbers of each type of receptor, in their peak sensitivities, and in the ratios of these types of receptors. ${ }^{24}$

In addition to these differences in the organization of receptors in members of our species, there are interpersonal differences (even among nonanomalous trichromats) in the filtering yellow pigment of the macula and the lens of the eye ([Hurvich, 1981], 113-116; see also the striking photographic evidence of this phenomenon in [Werner, 1998], 7) and in cone absorption spectra ([Boynton, 1979], 384). As noted by ([Clark, 1993], 164-170) and [Hurvich, 1981], 222-223), these sources of variation result in a non-trivial

types, and point out that a single surface can fall under multiple reflectance types, possibly including a first reflectance type represented by one type of visual system and a second reflectance type represented by another type of visual system:

Since a single surface falls under many different reflectance types ..., there need not be any conflict between color appearances across species. Goldfish and human beings see objects as having different colors, but reflectance physicalism gives no reason to suppose that if one species is right, then the other must be wrong (16).

Regarding this interspecies case of perceptual variation, then, Byrne and Hilbert want to deny that one of the variants is veridical at the expense of the others. Interestingly, however, in interpersonal or intrapersonal cases of perceptual variation (see $\S \S 3.2-3.3$ below), they want to accept that one of the variants is veridical at the expense of the others ([Byrne and Hilbert, 2003], 16-17, 56-57). They need to tell us, therefore, why they deny in some perceptual variation cases what they accept in other perceptual variation cases. In contrast, I consider it an advantage of the view presented here that it applies the argumentative strategy at issue in a completely consistent way across perceptual variation cases.

${ }^{23}$ Anomalous trichromats have trichromatic visual systems, but the spectral sensitivity of one of their three channels is shifted relative to normal subjects. Dichromatic visual systems encode color information only along two independent channels: human dichromats who lack functioning L-cones are called protanopes, while those who have no functioning M-cones are called deuteranopes. The remaining sort of dichromacy, in which S-cones do not function, is known as tritanopia, and is much rarer than both protanopia and deuteranopia. Monochromats encode color information only in one channel, and are responsive only to differences in brightness/lightness (not hue or saturation). Achromatopes are those who, due to damage to the visual cortex, are unable to make color discriminations at all.

${ }^{24}$ These results have been confirmed by several lines of converging research, including psychophysical methods ([Rushton and Baker, 1964], [Pokorny et al., 1991], [Cicerone and Nerger, 1989], [Vimal et al., 1989]), spectral electro-retinograms ([Jacobs and Neitz, 1993], [Jacobs and Deegan, 1997]), microspectophotometry ([Bowmaker and Dartnall, 1980], [Dartnall et al., 1983]), messenger RNA analysis ([Yamaguchi et al., 1998], [Hagstrom et al., 1998]), and retinal densitometry ([Roorda and Williams, 1999]). 
distribution of the loci for unique green between 490 and 520nm even among non-anomalous trichromats. ${ }^{25}$ Finally, there are various non-receptoral abnormalities of color vision due primarily to damage to areas of the visual cortex, known collectively as central achromatopsia.

Once again, these differences result in a range of perceptual variants, this time between the effects produced by a single objectively specified stimulus in different human visual systems. For example, subject $S_{1}$ 's visual system represents a spectral light of $505 \mathrm{~nm}$ as being greenish without being bluish or yellowish, while subject $S_{2}$ 's visual system represents the very same spectral light as being greenish and also bluish. Which of these conflicting representations of the color of the spectral light is veridical? As before, there are four possible choices: (i) we can declare that $S_{1}$ is correct and $S_{2}$ is incorrect; (ii) we can side with $S_{2}$ to the detriment of $S_{1}$; (iii) we can insist that neither $S_{1}$ nor $S_{2}$ veridically represents the color of the light; or (iv) we can admit that both visual systems are veridical. And, as in earlier instances of the master argument, I suggest that (i), (ii), and (iii) are all unmotivated and stipulative, and therefore advocate choice (iv). Namely, we should accept that if $x$ looks green to $S$, then $x$ is green for $S$.

Now, there is in the literature a standard response to these considerations - a response that attempts to give a principled motivation for favoring one of (i), (ii), or (iii). This response, which is advocated in some form by Locke, ([Peacocke, 1984], 60), ([Wright, 1992], 136-137), and [Harman, 1996], holds that (the visual system of) a subject $S$ that represents the color of $x$ does so veridically just in case $S$ 's representation of the color of $x$ matches with the representation of $x$ 's color by a standard observer of $S$ 's kind. Supposing that $S_{1}$ and $S_{2}$ are members of a common species (in the case at hand, they are both human beings), it is not unreasonable to hold that the relevant kind is that common species. On this view, then, we should choose among (i)-(iv) by asking whether one, the other, both, or neither, of $S_{1}$ 's and $S_{2}$ 's representations of the spectral light match that of the standard observer for human beings.

Of course, the strategy at hand will succeed only if there is a non-stipulative specification of what counts as a standard observer for human beings (if it is to be applied more generally, this strategy presupposes the possibility of a nonstipulative specification of what counts as a standard observer for an arbitrary species). One reason for optimism on this front comes from the intuition that certain observers in our own species are deficient (and not merely alternative) judges of color: for example, the U. S. Navy's refusal to accept even anomalous trichromats with perfect visual acuity as naval pilots presumably reflects an intuition that anomalous trichromats are seeing colors incorrectly, rather than just differently. ${ }^{26}$ Of course, these intuitions, by themselves, cannot give us a

\footnotetext{
${ }^{25}$ Unique green is defined as that green hue that is neither bluish nor yellowish in appearance; the locus of unique green for a given observer is the spectral frequency at which monochromatic light appears unique green to that observer. As it happens, there is a similarly non-trivial distribution for loci of the other unique hues as well, although the standard deviation of the distribution is largest for unique green.

${ }^{26}$ As the officer at the Brooklyn Navy recruiting office who took my call explained, "Honey,
} 
full specification of what counts as a normal perceiver. However, there are at least two ways in which one might hope to elaborate these intuitions into a more complete specification.

First, one might hold that such standards are set by numerical majority: that an observer counts as a standard observer if his visual system is sufficiently like (in the right respects) the visual systems of a majority (or a weighted majority, or whatever) of members of the species. This proposal has the defect that it pushes back, rather than resolves, the problem of specifying a standard: now we owe a non-stipulative specification of the relevant dimensions for comparing visual systems, as well as a non-stipulative specification of the threshold for judging that two visual systems are sufficiently alike. Moreover, even putting these problems aside, a number of writers have noted that adverting to the larger subpopulation leaves open the possibility that the standards could change because of mass micro-surgery or selective breeding. ${ }^{27}$ But if the veridicality of a perceptual variant turns on its matching against the perception of a standard observer, this would mean that a perceptual variant that erroneously represented the color of $x$ at $t_{1}$ could come to represent the color of $x$ veridically at $t_{2}$ in the absence of any intrinsic change in $x$ - a result that would surely be unacceptable to those who take colors to be non-relational properties.

A second way in which one might hope to elaborate intuitions about standard observers might appeal to some of the more elaborate specifications of standard perceivers designed for particular scientific and industrial purposes. The best established and most frequently used candidate specification of this sort is the CIE 1931 Standard Observer (cf. [Wyszecki and Stiles, 1967]), constructed by the CIE for the purpose of standardizing descriptions of the color-matching properties of lights. ${ }^{28}$ The CIE 1931 Standard Observer is in fact a set of triples (tristimulus values) corresponding to a range of spectral lights; each triple specifies coefficients for three selected primaries such that the resulting linear combination will perceptually match the corresponding spectral light for a so-called average observer. The average observer in question is, as it happens, a construction formed by averaging the results of actual observers from two different experiments. ${ }^{29}$

\footnotetext{
if you're color blind, it just ain't happening."

${ }^{27}$ The by-now standard case, which I believe originates in ([Bennett, 1968], 105-107) involves phenol, which apparently tastes bitter to about seventy percent of the population and is tasteless to about thirty percent of the population. Is phenol bitter or not? As Bennett points out, if one answers that phenol is bitter on the grounds that it tastes bitter to a larger sub-population, then we could change the properties of phenol - we could make it go from being bitter to not being bitter - by mass micro-surgery or selective breeding. (Cf. [Bennett, 1971], chapter IV; [McGinn, 1983], 9-10; [Jackson and Pargetter, 1987], 71-72.)

${ }^{28}$ The CIE (Commission International de l'Eclairage) is an international organization responsible for recommending standards and procedures for light and lighting.

${ }^{29}$ The CIE 1931 Standard Observer is used for purposes involving stimuli small enough that they fall within the fovea (roughly 2 degrees of visual angle). The data underlying this specification come from independent investigations by Guild and Wright; the CIE 1931 Standard Observer was calculated from these data by first transforming the two sets of results into a common coordinate system and then averaging the transformed values.

Investigators have found that the CIE 1931 Standard Observer is inadequate for many ex-
} 
Unfortunately, there are reasons for doubting that the CIE 1931 Standard Observer will serve the purposes at hand. First, as noted in ([Hardin, 1988], 76-82), the CIE 1931 Standard Observer, like other scientific and industrial specifications that have been articulated, is a statistical construct drawn from a range of actual individuals, but that differ significantly from most (perhaps as many as 90\% of) human visual systems ([Evans, 1948], 196-197); therefore, fixing the colors by appeal to such standards would commit one to the unpalatable conclusion that the color discriminations of most (perhaps as many as $90 \%$ of) human visual systems are erroneous. Second, specifications like the CIE 1931 Standard Observer are stipulatively chosen for particular purposes (mathematical convenience, industrial standardization). While this makes those standards entirely appropriate for use in the context of those purposes, it means that they are stipulative - they are explicitly stipulated to serve (mathematical, industrial) purposes. Which is to say that appeals to these standards cannot be, as we had hoped, non-stipulative ways of deciding between a range of perceptual variants. This lesson is reinforced by the plurality of standards itself (for example, we have seen that even for the restricted purposes of colorimetric matching, the CIE recommends different standards for stimuli under 4 degrees and stimuli over 4 degrees of visual angle). Each standard is clearly appropriate to the particular purposes for which it was designed, but clearly inappropriate for use in a range of other purposes one might have (including purposes for which users felt the need to invent distinct standards), and therefore not plausible as the fully general understanding of normality that one would need to respond to the argument from perceptual variation.

For these reasons, it would seem that the usual specifications of standard observers for species will not provide a non-stipulative response to the argument from perceptual variation. Moreover, since these are our best motivated standards, it's extremely doubtful that some other specification will serve us better in this context; appeals to less motivated standards are ipso facto more stipulative, and therefore less persuasive as responses to the argument from perceptual variation.

\subsection{Intrapersonal Differences: Within-Subject Variations}

I've applied the argument from perceptual variation to cases of variation between members of different species (§3.1) and between members of a given species (§3.2); in this section I want to apply the same argument to cases of perceptual variation (with respect to color) within subjects.

That there is such intrapersonal perceptual variation will be familiar to anyone who has ever put on or removed tinted sunglasses, adjusted the lighting in a room, or been surprised by changes in the appearance of garments once removed from the flattering viewing conditions of the store.

periments involving larger stimuli; for this reason, the CIE recommends the use of another standard — the CIE 1964 Standard Observer — based on work of Stiles, Burch, and Speranskaya, for stimuli of more than about 4 degrees of visual angle.

See [MacAdam, 1997] for details concerning these standards. 
In all these cases, there is a range of perceptual variants, this time between the effects produced by a single objectively specified stimulus in a single human visual system, across variations in the viewing conditions. For example, subject $S_{1}$ 's visual system represents a certain garment one way under the viewing conditions $C_{1}$ inside the store, and another way under the viewing conditions $\mathrm{C}_{2}$ outside the store. Which of these conflicting representations of the color of the garment is veridical? And why? Just as in earlier cases, there are four possible choices: (i) we can declare that the representation in $C_{1}$ is correct and that that in $C_{2}$ is incorrect; (ii) we can side with the representation in $C_{2}$ to the detriment of the representation in $C_{1}$; (iii) we can insist that neither the representation in $C_{1}$ nor that in $C_{2}$ veridically represents the color of the garment; or (iv) we can admit that both of the representations (that in $C_{1}$ and that in $C_{2}$ ) are veridical. And, just as in earlier cases, I suggest that (i), (ii), and (iii) are all unmotivated and stipulative, and therefore advocate choice (iv). Namely, we should accept that if $x$ looks green to $S$ in $C$, then is green for $S$ in C.

But, as in the instance of the master argument that concerned betweensubject (within-species) variations, there persists an intuition that we might give a motivated, non-stipulative reason for favoring one of options (i)-(iii). For it seems plausible that some viewing conditions are just not conducive to the veridical perception of colors. This is why, for example, we chide (rather than simply disagree with) the museum-goer who neglects to remove his sunglasses; similarly, we would be foolish (and not just eccentric) to choose a tie to match a suit without first turning on the lights. Once again, such intuitions suggest that we might attempt to specify some set of canonical or standard conditions for perceiving colors, and then choose between (i)-(iv) by asking whether one, the other, both, or neither, of the representations of the color of the garment in $C_{1}$ and $C_{2}$ matches the representation of the color of the garment in standard conditions.

But once again, there are reasons for doubting that there exists the kind of non-stipulative specification of standard conditions for color perception that this strategy demands. It is true that, as in the case of standard observers, there are scientific and industrial recipes for standard conditions (cf. [American Society for Testing and Materials, 1968], [Judd and Wyszecki, 1963], [Kelly and Judd, 1976], [Wyszecki and Stiles, 1967]); but, once again, these are ill-suited to our purposes. To see why, consider a notion of standard conditions based on the instructions for the Munsell color chips, ${ }^{30}$ that state that "the samples should be placed against a dark achromatic background and 'colors should be arranged under North Daylight or scientific daylight having a color temperature of from 6500 degrees to 7500 degrees Kelvin. Colors should be illuminated at 90 degrees and viewed at 45 degrees, or the exact opposite of these conditions' "

\footnotetext{
${ }^{30}$ The Munsell color system is a widely used set of color samples (chips); these samples are used as standards in terms of which the colors of test samples can be described. Cf. [Munsell, 1946] and [Munsell Color Company, 1976].
} 
([Hardin, 1988], 68). ${ }^{31}$ While these conditions are adequate for standard uses of the Munsell chips, they cannot be taken as a general specification for standard conditions. For example, these conditions could not be used to specify the colors of stars, neon tubes, rainbows, and other cases where the Munsell-specific conditions cannot be met. ${ }^{32}$ Moreover, this set of conditions is not amenable to the colors of directionally reflective materials, materials whose color is dependent on use, or translucent materials. ${ }^{33}$ For these reasons, the Munsell-inspired specification of standard conditions is inadequate as a fully general proposal. Of course, we could answer some or all of these complaints by clinging to the specification from the Munsell instructions if we are willing to declare that the problematic phenomena are all color-illusions; however, without independent motivation, such declarations will seem disturbingly ad hoc.

If the Munsell-inspired proposal fails because of the vastly different sorts of situations in which we want to attribute colors to objects, a natural suggestion would be to divide objects into different types, and then specify standard conditions for each type. Thus, on such a proposal, we could specify separately standard conditions for opaque surface colors, volume colors, film colors, selfluminous colors, and so on. However, this procedure, too, runs into trouble quickly. Considering just surface color, for example, we have seen above that

\footnotetext{
${ }^{31}$ Even this apparently quite specific formulation of standard conditions leaves out many factors relevant to the way $x$ looks to $S$. For example, Alan Gilchrist and his students have shown me several compelling examples in which the perceived lightness of $x$ at time $t$ depends crucially on factors such as the relative lightness of other objects seen at $t$, the relative lightness of $x$ at times earlier than $t$, the relative proportions of the visual field occupied by $x$ and objects of different lightness from $x$ at $t$, and so on. They also have cases showing that the perceived lightness of $x$ depends on the perceptual groups in which $x$ is classified: the influence of the relative lightnesses of objects in a geometrical configuration $G$ on the perceived lightness of $x$ depends on the extent to which $x$ is parsed by the visual system as being part of $G$.

${ }^{32}$ Perhaps this limitation is one of practice rather than principle in certain of these cases, but arguably it is necessarily insuperable in others, such as that of the rainbow.

It is not obvious that rainbows have any definite location; if not, then the proposal at hand is necessarily inapplicable to rainbows. Suppose, therefore, and not unreasonably, that a rainbow has the location of the water drops refraction through which is responsible for its appearance. When light strikes the water/air interface at the front of a drop, it is dispersed by wavelengths - longer wavelengths are bent less than shorter wavelengths. If the angle between the refracted light and the normal to the drop surface is greater than a critical angle $\left(48^{\circ}\right.$ for water), the light is then reflected off the back of the drop, and refracted/dispersed again when it passes through the front of the drop, at which point it can go on to strike local visual systems. The total angle from the incoming light path to the eye (with the back of the drop at the apex) is $40^{\circ}$ at the violet end and $42^{\circ}$ at the red end of the rainbow (cf. Descartes' classic account in the Meteorology, Discourse 8, and, for a more modern treatment, [Humphreys, 1964], 476500.) Consequently, on the present supposition about the location of rainbows, no rainbow can be viewed at an angle of 45 degrees or an angle of 90 degrees. Moreover, since this restriction on viewing angles appears to be necessary, appealing to counterfactuals about how things would have looked in standard conditions won't resolve this difficulty. The worry, then, is that the proposal under consideration would entail that (necessarily) rainbows are not among the bearers of colors. This result seems highly revisionary: rainbows are often offered as paradigmatic instances of color properties.

${ }^{33}$ Briefly, these conditions could assign only one of what seem to be equally plausible candidates for the color of directionally reflective materials, and could not assign any well-defined color to materials whose color is dependent on use or to translucent materials.
} 
a given surface patch looks different in respect of color to a given observer as a function of the region surrounding the patch. Moreover, as argued in $\S 2.2$, there is no principled criterion that favors just one from among the array of perceptual variants.

Furthermore, contrast effects are not the only worries; how a surface looks to a given subject depends also on the choice of magnitudes for such values as size and resolution of the field of view, angular size of the stimulus, and state of adaptation of the viewer - choices for which there are no obviously principled criteria. ${ }^{34}$ Similarly, a set of standard conditions for surfaces would need to include a choice of illumination, but each CIE standard illuminant (ostensibly the best candidates for a principled choice of standard conditions of illumination) has metameric pairs that are not metamers under other illuminants; again, it is hard to see how to make a non-arbitrary choice among the illuminants. ${ }^{35}$

Once again, it seems that the standardized specifications of standard conditions designed for use in particular laboratory or industrial purposes will not provide a non-stipulative response to the argument from perceptual variation. And once again, since such scientific and industrial standards are our best motivated candidates, it seems unreasonably optimistic to think that a more successful specification of standard conditions is in the offing. Consequently, it seems unreasonably optimistic to think that an appeal to standard conditions can block the intrapersonal version of the argument from perceptual variation.

\section{Color and Ordinary Color Language}

I have argued that the colors of things depend on a large number of features of visual systems and viewing conditions, and then argued that attempts to stipulate away such dependencies fail. Consequently, I suggested, an adequate theory of color should understand colors as relational properties - namely, as properties constituted in terms of relations between objects, visual systems, and viewing conditions. However, there are a number of reasons for thinking that this view conflicts with ordinary uses of color language. In this section I'll consider and respond to several related objections to relationalism based on ordinary color language, and then explain how the view connects with ordinary color discourse.

A first prima facie objection against relationalism about color comes from the evidence that ordinary color ascriptions seem to be unrelativized. Ordinary

\footnotetext{
${ }^{34}$ One natural suggestion is that the standard condition for viewing should be defined as the point at which maximum resolution is available. However, as Hardin points out, this strategy will fail if there is no point of maximum resolution, which is what is suggested by the variation in size of the receptive fields of retinal neural units ([Hardin, 1988], 71).

${ }^{35}$ The CIE has specified several standard illuminants for laboratory and industrial use in terms of their relative spectral power distributions. The most important of these are standard illuminant A, standard illuminant B, standard illuminant $\mathrm{C}$, and standard illuminant $\mathrm{D}_{65}$.

Metameric pairs are pairs of physically different stimuli (typically distinguished in terms of their having different spectral reflectance distributions or spectral power distributions) that are perceptual matches for a given observer and a given viewing condition.
} 
speakers say 'the lemon is yellow', rather than 'the lemon is yellow for $S$ in $C$ ': when we discuss the colors of clothing, fruit, traffic signals, beer, and so on, it is no part of our explicit color discourse to fill in the parameters emphasized by relationalism. Therefore, the objection goes, the predictions relationalism makes about color properties are directly falsified by ordinary color ascriptions.

A second objection alleges that relationalism about color is too permissive. If relationalism is right, then relational properties constituted in terms of relations between objects and visual systems very different from our own, or in very strange viewing circumstances, will be counted as genuine colors. But attributions of these colors can strain credulity; for example, it can seem odd to say that how things look to dichromats reveals colors that those things have, or that a ripe raspberry is really gray in situations of extremely low illumination. However, if there is no principled way of excluding these attributions, as urged in $\S 3$, then the relationalist must endorse them. Once again, the consequences of relationalism seem to be at odds with our ordinary thought and talk about color.

A third, closely related objection alleges that relationalism proliferates color attributions too liberally. The objection here is not, as in the case of the previous worry, that the color attributions a relationalist must endorse are themselves unpalatable. Rather, it is that, even if all of the attributions licensed by relationalist views were plausible on their own, it would still seem unreasonable to accept all of them at once. According to the relationalist, an object is not merely red - it is red to one perceiver in one circumstance, blue to a second perceiver in a second circumstance, green to a third perceiver in a third circumstance, and so on (infinitely) into the night. But, the objection goes, this pluralism goes too far; putting aside such cases as the "unsteady" colors on the backs of compact disks and credit card holograms, we are typically inclined to attribute only a few colors to ordinary objects — certainly only finitely many, and perhaps only one. ${ }^{36}$

A fourth and final objection notes that ordinary talk about color presupposes the possibility of agreement, disagreement, and errors of color attribution that seems, prima facie, difficult to reconcile with relationalism. If $S_{1}$ utters (P1) because the raspberry looks gray when viewed in a circumstance $C_{1}$ where there is extremely low illumination, $S_{2}$ says something pertinent, and indeed disagrees with $S_{1}$ when she utters (P2) because the raspberry looks red when viewed in a circumstance $C_{2}$ where there is strong illumination by direct sunlight.

(P1) This ripe raspberry is gray in $C_{1}$.

(P2) This ripe raspberry is not gray in $C_{2}$.

If relationalism were true, then it seems that the two color attributions just considered could not conflict, just as the following two sentences cannot conflict:

(R1) It is raining in Vancouver.

\footnotetext{
${ }^{36}$ The distinction between "unsteady" and "standing" colors is made by [Johnston, 1992], 141; Johnston attributes it to [Rossotti, 1983], chapters 3 and 4.
} 
(R2) It is not raining in San Diego.

Since the meteorological situation is clearly constituted in terms of relations to locations, and because the meteorological attributions (R1) and (R2) are explicitly relativized to different cities, the two claims cannot conflict (nor can they be in agreement). ${ }^{37}$ Similarly, if colors are constituted in terms of relations to viewing circumstances (as per relationalism), then since the color attributions (P1) and (P2) are explicitly relativized to different viewing circumstances, the two claims cannot conflict (nor can they be in agreement). But this is absurd: surely we can agree and disagree about the colors of objects. (The intuition that color attributions can disagree may be even stronger in the case where $S_{1}=S_{2}$, and where the subject makes a second attribution as a way of correcting a first.) Similarly, if color relationalism were true, it might seem difficult to see how (P1) could ever be erroneous, insofar as it could not be corrected by (P2) or (nearly) any other color attribution. Again, this is absurd: an account of color that precludes erroneous color attributions is not a theory we can accept. ${ }^{38}$

I believe the objections just canvased are extremely important, but that they do not refute the relationalist view I have advocated. What these objections show, I believe, is that ordinary thought and talk about colors presupposes particular ways of filling in the parameters to which color properties are relativized, but that these presupposed parameters are tacit in our ordinary thought and talk. I now propose to explain how this point answers the objections considered.

Consider the first objection - that color discourse makes no explicit mention of the parameters to which the relationalist claims colors are relativized. I stand by the relationalist claim that colors are constituted in terms of relations to visual systems and viewing circumstances, but I also claim that the presuppositions of ordinary thought and talk about color tacitly provide us with values for these parameters. In particular, I suggest, we fill in these parameters by tacitly generalizing from our own case or the cases of organisms like us. ${ }^{39}$

\footnotetext{
${ }^{37}$ Needless to say, it is inessential to the success of the example that (R1) and (R2) are analytic.

${ }^{38}$ See ([Matthen, 2001], note 10) and ([Byrne and Hilbert, 2003], 57-58) for two versions of the objection that color relationalism precludes erroneous color attributions.

${ }^{39}$ In this vein, [Lewis, 1997] claims that color attributions are always tacitly relativized to human individuals and perceptual circumstances we take to be of the prevailing sort:

'Normal light' can be explained in terms of the range of illumination that most people - actually, nowadays, and hereabouts - mostly encounter. Likewise, mutatis mutandis, for normal capacities and normal surroundings.... I do not suppose it is incumbent on folk psychophysics to do much by way of listing abnormal cases - if it tried, it would soon outrun common knowledge. A statistical conception, rigidified to actuality and nowadays and hereabouts, should suffice ([Lewis, 1997], 327)

A consequence of Lewis's view is that we cannot relativize to different visual systems and viewing conditions when we so choose. But, I suggest, this consequence is false: we can choose to make color ascriptions relative to different visual systems and viewing conditions. Of course, I agree that Lewis's proposal explains much of our ordinary use of color concepts; however, I find his restriction ultimately too confining. My suggestion that the tacit relativization is a cancellable presupposition — one that is typically in place but capable of being overridden - seems to me to enjoy all the benefits and none of the disadvantages of Lewis's proposal.
} 
Thus, we say that $x$ is green (simpliciter) when we mean that $x$ looks green to visual systems like our own and in viewing conditions like those we typically encounter. That ordinary discourse does not make these values explicit shows not that they are not present, but only that they are tacit.

On the other hand, that we presuppose these tacit values answers the second objection - it explains why relationalism does not result in an unduly permissive attitude toward color attributions. We would persist in our disinclination to enjoy salmon steaks that looked indigo to us, even after being told that the steaks are pink for other sorts of visual systems or for our visual systems under different (non-actual) viewing conditions. The reason for this, on the present account, is that the visual systems to which we ordinarily and tacitly presuppose relativization are those of organisms like ourselves. While it may be true that the curious-looking salmon steaks are indeed pink for another sort of creature, facts about creatures unlike us are quite low in importance, given our pragmatic interests at the dinner table. What we care about at that moment is the color of the steaks for creatures like ourselves, and the inductions supported by those color attributions. ${ }^{40}$ Thus, my view explains the unease in the thought that the way things look to dichromat human beings and snakes, or the way things look to us in conditions of very low illumination (for example) correctly reveal colors that those things have; on the present view, this unease is the result of a violation of pragmatic maxims enjoining relevance to our conversational presuppositions (namely, to our presuppositions about particular sorts of visual systems and viewing conditions).

\footnotetext{
${ }^{40}$ What about the anomalous trichromats (/achromatopes/monochromats/dichromats/tetrachromats) among us? When they use ordinary color language, do they tacitly presuppose a relativization to visual systems like their own, or to the visual systems of non-anomalous trichromats? I am inclined to think that human beings whose visual systems are in the minority typically use color terms in the same way as the majority — viz., that they presuppose relativization to normal trichromatic visual systems if they are aware of the differences between themselves and the rest of the population. (Presumably if they were unaware of such differences they would not presuppose relativization to other visual systems.) Anecdotal evidence supporting this claim comes from a number of sources.

First, consider this report from Roger Shepard's experiments on dichromats:

One particularly articulate protan insisted that although he could not distinguish the (highly saturated) red and green we showed him, neither of these papers came anywhere near matching up to the vivid red and green he could imagine! In a sense, then, the internal representation of colors appears to be three-dimensional even for those who, owing to a purely sensory deficit, can only discriminate externally presented colors along two dimensions.... ([Shepard, 1992], 339).

Further support comes from a conversation, reported by Oliver Sacks, in which an achromatope recognizes a distinction in color not marked by his visual system:

"But what about bananas, let's say — can you distinguish the yellow from the green ones?" Bob asked.

"Not always," James replied. "Pale green' may look the same to me as 'yellow"” ([Sacks, 1996], 32; shudder-quotes in original).

Finally, my conjecture is (surprisingly) borne out by Jameson's and Hurvich's reports that protanopes and deuteranopes whose performance on color similarity orderings reveals their lack of red-green discrimination "nevertheless use reddish and greenish hue terms appropriately when instructed to name the same test colors..." ([Jameson and Hurvich, 1978], 146).
} 
The present view defuses the threatened proliferation of color attributions along similar lines. It is true that, according to relationalism, ordinary objects have infinitely many colors (see $\$ 5.1$ ). However, only a tiny finite minority of these colors have any relevance to perceivers to whom we tacitly presuppose relativization, in the viewing circumstances to which we tacitly presuppose relativization. Indeed, given that the restrictions on perceivers and viewing conditions tacitly presupposed by ordinary thought and talk about color are so confining, we can typically talk about the (unique) color of an object without any trouble, unless we start making psychophysical comparisons of the sort discussed in $\S 3$ - only when directly confronted with this range of psychophysical variation do we recognize that our assumptions about the uniqueness of colors are insupportable. This point is well-illustrated by the case of meteorological attribution considered above. One may choose whether or not to bring an umbrella to work partly as a result of the answer one gets to the question, "Is it raining?" Of course, this question hides a tacit locational parameter, and indeed employs a singular pronoun ('it'), that allows us to talk about the (unique) state of the weather without any trouble, unless we start making detailed meteorological comparisons with friends in other cities - only when directly confronted with this range of meteorological variation do we recognize that our assumptions about the uniqueness of of the meteorological situation are insupportable. Thus, the intuition that relationalism attributes too many colors is, I claim, a result of the pragmatic presuppositions we bring to bear in ordinary thought and talk about color, and as such is compatible with relationalism.

The same point can be used to answer the objection that relationalism would preclude agreement, disagreement, and error with respect to color attributions. Speakers can agree and disagree about the colors of objects because the visual systems and viewing circumstances to which ordinary color attributions are tacitly relativized are not individuated so finely that they are unrepeatable singletons, but include the visual systems of other human beings like ourselves and the viewing conditions they typically encounter. That is, (P1) and (P2) should be understood not as analogous to the obviously independent pair (R1) and (R2), but to the obviously not independent pair (R1) and (R3):

(R1) It is raining in Vancouver.

(R3) It is not raining in Vancouver.

Because the locational parameters in (R1) and (R3) match, these statements can be in agreement or disagreement: two people who utter (R1) will be in agreement, and someone who utters (R1) will disagree with someone who utters (R3). Similarly, since the tacit relativizations I presuppose in producing and understanding ordinary color attributions match the tacit relativizations you presuppose in producing and understanding ordinary color attributions, our attributions can be in agreement or disagreement.

A similar point permits an account of errors of color attribution. It is true that, if $x$ looks red to $S$ in $C$, then relationalism implies that $x$ is red to $S$ in $C$; so far, then, no error. However, if $S$ or $C$ lie outside the conditions for 
normality presupposed by our ordinary use of color language, then we can recognize a sense in which the way $x$ looks to $S$ in $C$ can be erroneous; viz., that it does not match the way $x$ looks to $S^{\prime}$ in $C^{\prime}$, where $S^{\prime}$ and $C^{\prime}$ are the sorts of perceivers and viewing conditions we take to be normal. And indeed, this description appears to characterize exactly the kinds of cases we would ordinarily (pre-theoretically) call color illusions or errors of color vision. In such cases, the perceiver or viewing conditions (typically the latter) are deliberately manipulated so that they depart from our presuppositions, and this leads perceivers to the (completely understandable, but in such cases erroneous) belief that things that look red to them in those conditions are red simpliciter — viz., red for normal perceivers in normal conditions. Consequently, relationalism allows for errors of color attribution. ${ }^{41}$

I take seriously the objections concerning ordinary color language considered so far, and therefore it is important to me that the claims about tacit presupposition that I have invoked enable me to meet these objections. However, apart from providing answers to these objections, the tacit relativization I am claiming underlies ordinary uses of color concepts and color language is supported by several independent considerations.

Not least among these is that this relativization allows us to pay our due to the anthropocentrism inherent in our thought and talk about color without giving in to an all out species-chauvinism that would make color vision in other organisms a conceptual impossibility. ${ }^{42}$ I can agree with Hilbert that "discussions of color ontology, as well as a large part of color science, are, after all, primarily concerned with a property that human beings perceive, reflect on, and talk about" ([Hilbert, 1992], 39). The way to gloss this quotation, given what I've said about the tacit relativization to our own kinds of visual systems and viewing conditions, is that the tacitly relativized properties we ordinarily talk about are indeed of only parochial interest. However, because we are perfectly capable of dropping the tacit parameters, instead choosing to relativize the way things look to other visual systems and viewing conditions when it suits us, we are capable of talking about colors and color vision more expansively when this is appropriate (pace Hilbert). ${ }^{43}$ I suggest that ordinary language vindicates

\footnotetext{
41 The relationalist can allow for another (less ordinary) sense of error by excluding cases that involve deviant causal chains. For example, consider the telekenetically chromatic tomato: in addition to its ordinary capacity to look red, this tomato has a surface property that directly (i.e., without retinal stimulation of any kind) affects visual cortices of perceivers in such a way as to produce in them a green appearance. The green appearance of the telekenetically chromatic tomato is due to a deviant causal chain; as such, there are theory-independent reasons for counting it a pathological case. Hence, the relationalist is within her rights in calling this color appearance erroneous.

${ }^{42}$ In this connection, [Matthen, 1999] complains that many leading accounts of color are unacceptably species-chauvinistic - that their understanding of color properties primarily in terms of the effects of these properties on beings of our own species results in an inappropriately limited theory. My account evades this worry because, although it gives pride of place to our species-chauvinistic presuppositions in fixing ordinary uses of color terms, it allows that these presuppositions are cancellable, and therefore correctly predicts that we can talk about color for other more or less outlandish organisms (and viewing circumstances) in a perfectly straightforward sense.

${ }^{43}$ Hilbert continues the quotation above as follows: "If it turns out that this property is not
} 
this prediction, and therefore makes the present view preferable to more strictly species-chauvinist views such as Hilbert's.

Another consequence of the tacit references I have claimed are presupposed by ordinary color thought and talk is that color concepts contain vague elements. There are clear cases of visual systems like ours (normal trichromatic systems in other human beings), clear cases of visual systems unlike ours (the systems found in mantis shrimp that contain ten different kinds of cones [Cronin and Marshall, 1989] or the dichromatic visual systems of squirrels ([Thompson, 1995], 145)), and borderline cases of visual systems like ours (normal trichromat human beings who disagree with us about the spectral locus for unique green). Similarly, there are clear cases of viewing conditions like those we typically encounter (from 90 degrees at a distance of one meter under flat illumination of 7000 degrees Kelvin with uniform surround), clear cases of viewing conditions unlike those we typically encounter (at a depth of 3 miles underwater, say), and borderline cases of viewing conditions like those we typically encounter (lit by a candle, or with a surround field consisting of thin diagonal blue lines). ${ }^{44}$ If such vague elements really are presupposed by our uses of color terms, as I claim, then it should be vague as well whether we are prepared to say that something that looks green to such organisms under such circumstances really is green (in the ordinary, tacitly relativized sense). And this is just what typical reactions to the cases in $\S \S 3.1-3.3$ reveal: although we may be sure that some of the cases should count and that some should not, there are many cases where we are not clear what to say.

In addition, the view I have proposed allows us to understand the various scientific and industrial specifications of standard observers and viewing conditions as precisifications designed for particular purposes (which is just what they appear to be) rather than as absolute standards for fixing the extensions of the color properties. Again, this is what we should expect if color language is vague in the respect I have claimed; analogously, we might establish stipulative boundaries for the extension of a vague term such as 'bald' for particular industrial or scientific reasons (perhaps we need to assemble an army to fight an enemy who happens to be particularly skilled at capturing bald soldiers, and therefore decide to draft all men with at least 10,000 hairs on their heads) without thereby claiming to have found determinate boundaries between the negative and positive extensions of the term.

perceived by some other kinds of organisms that is neither surprising nor a challenge to the adequacy of our accounts of this property of particularly human interest." It is this claim, I suggest, that is unpalatably restrictive, and unmotivated so long as there are less revisionary alternatives (such as relationalism) in the running.

${ }^{44}$ It is inessential to the claim I am making that the vagueness of these comparisons runs along several independent dimensions (e.g., typicality of viewing angle, light source, atmospheric composition). In any case, it's worth noticing that, although discussions of vagueness in the philosophical literature often proceed under the pretense that the cases they discuss are vague only along one dimension (number of grains that compose a heap, number of hairs on a head), this assumption is false even in the paradigm cases. After all, heapness depends on such additional vague factors as shape and spatial proximity of the collection, and baldness depends on such additional vague factors as length of the hair and size of the head (cf. [McLaughlin, 1997], 216). 
Finally, the present account evades a difficulty faced by other accounts that attempt to explain agreement, disagreement, and error of color attributions in terms of assumptions about standard perceivers and standard viewing conditions. Several philosophers have appealed to such assumptions at work in our thought and talk about color in order to explain agreement, disagreement, and error of color attribution, but have attempted to build these assumptions into the metaphysics of colors themselves, rather than into a separate account of color attribution. Thus, for example, a number of writers, under the inspiration of one line in Locke's discussion, appear to have held a view according to which (roughly) red is the disposition to look red to standard perceivers in standard viewing conditions (cf. ([Peacocke, 1984], 60), ([Wright, 1992], 136137), and [Harman, 1996]). Unfortunately, as I have argued (§3), there is no non-arbitrary, objective, metaphysically well-motivated way in which to single out a standard perceiver and a standard viewing condition; but if so, then the accounts in question cannot give an understanding of red that is non-arbitrary, objective, and metaphysically well-motivated.

The view I am advocating does not have this consequence. For, insofar as my view adverts to a standard perceiver and standard viewing conditions, it does so in its account of the conversational presuppositions at work in ordinary thought and talk about color. Unlike the writers mentioned above, I claim not that the property red is relativized to standard perceivers and standard viewing conditions, but that ordinary color attributions are tacitly relativized to standard perceivers and standard viewing conditions. Consequently, if there is no nonarbitrary, objective, metaphysically well-motivated way in which to single out standard perceivers and standard viewing conditions, this would not mean for me (as it would for the writers mentioned above) that there is no non-arbitrary, objective, and metaphysically well-motivated understanding of red. On the contrary, I insist that color properties are of the form red for $S$ in $C$, and that these relational properties are perfectly non-arbitrary, objective, and metaphysically well-motivated. It may be that the presuppositions about standard perceivers and viewing conditions that I claim are at work in ordinary color attributions are arbitrary (viz., stipulative, conventional); but surely presuppositions that are arbitrary in this sense can serve ordinary needs (just as, for example, the convention enjoining that motorists within a jurisdiction should drive on the right rather than the left serves ordinary needs, despite being arbitrary in the same sense). In any case, if non-arbitrary color attributions are needed for more recondite metaphysical or scientific purposes, these are available as well: we can always revert to wholly objective attributions of the relational color properties (e.g., red for $S$ in $C$ ).

\section{Ontological Objections}

In $\S 4$ I defended relationalism against a number of concerns rooted in the ordinary language of color attributions. In this section, I want to respond to some more directly ontological objections against relationalism. 


\subsection{A Chromatic Explosion Defused}

A first ontological objection is related to a worry raised in $\S 4$; there the worry was that relationalism issued too many color attributions - more color attributions, that is, than seem reasonable by the standards of our ordinary thought and talk about color. But, ordinary language aside, there is a further, purely ontological worry that relationalism populates the world with too many colors - more colors, that is, than seem reasonable by the standards of any plausibly parsimonious ontology.

Again, relationalism says that a ripe tomato is not merely red, but red to one perceiver in one circumstance, blue to a second perceiver in a second circumstance, green to a third perceiver in a third circumstance, and so on ad infinitum. Thus, relationalism not only recognizes infinitely many color properties, but also attributes infinitely many colors to every ordinary object. ${ }^{45}$ One might object that such a chromatic explosion is unacceptable.

However, I do not find anything unreasonable in either the relationalist's recognition of infinitely many colors or in her attribution of infinitely many colors to ordinary objects, so long as (per relationalism) colors are understood as relational properties.

To see the point, consider this analogy. There is a relation that holds of an object and a number just in case the set of fingers attached to the object has a cardinality less than the number. This relation holds between pairs — pairs of objects and numbers; but by fixing a number, we single out a relational property that relates objects to that number. ${ }^{46}$ For example, fixing the number seven, we single out the relational property having fewer than seven fingers that relates things to the number seven in a particular way; call this relational property ' $F_{7}$ '. Your left hand is in the extension of $F_{7}$, assuming it has fewer than seven fingers - your left hand is related to the number seven in the way required of things

\footnotetext{
${ }^{45}$ Objection: Relationalism does indeed seem to require the attribution of a large number of colors to an ordinary tomato, but why believe that it requires the attribution of infinitely many colors to the ripe tomato?

Response: Here is a valid argument for the disputed conclusion:

(P1) For any actual or possible observer of the ripe tomato $S$ and any actual or possible perceptual circumstance $C$ under which the ripe tomato can be perceived, red for $S$ in $C$ is a color that the ripe tomato exemplifies.

(P2) There are infinitely many actual or possible observers of the ripe tomato and infinitely many actual or possible circumstances under which the ripe tomato can be perceived.

(P3) If $S_{1} \neq S_{2}$ or $C_{1} \neq C_{2}$, then there is some possible object that exemplifies red for $S_{1}$ in $C_{1}$ while failing to exemplify red for $S_{2}$ in $C_{2}$.

(P4) For any colors $P$ and $Q, P=Q$ only if, necessarily, $P$ and $Q$ coincide in extension.

(C) Therefore, the ripe tomato exemplifies infinitely many colors.

The relationalist is explicitly committed to $(\mathrm{P} 1)$, but not - qua relationalist - to (P2)-(P4). On the other hand, I am prepared to concede (P2)-(P4) for the purposes of discussion. In this section I shall argue that no unacceptable consequences follow for the relationalist from this concessive assumption. (That said, if our lack of sympathy for (P2)-(P4) prevents us from endorsing (C), then the problem for relationalism considered in this section evaporates.)

${ }^{46}$ This is an instance of the procedure for generating relational properties from binary relations that [Humberstone, 1996] calls 'place-fixing' (213-215).
} 
that exemplify $F_{7}$. If so, then your left hand also exemplifies the relational property $F_{8}=$ having fewer than eight fingers, and it exemplifies the relational property $F_{9}=$ having fewer than nine fingers - your left hand is related to the numbers eight and nine in the ways required of things that exemplify $F_{8}$ and $F_{9}$. Indeed, it seems clear, we could continue this banal exercise forever. That is, there seem to exist infinitely many relational properties that relate things to numbers in the way we are imagining (viz., $F_{7}, F_{8}, F_{9}, \ldots$ ), and it seems that your left hand will exemplify infinitely many of these relational properties.

In my view, the relationalist's chromatic explosion is no more ontologically worrisome than the case of the left hand. The relationalist holds that a ripe tomato has the relational property red for $S_{1}$ in $C_{1}$ - the tomato is related to $S_{1}$ in $C_{1}$ in the way required of things that exemplify that color property. She also holds that the very same ripe tomato has the relational property blue for $S_{2}$ in $C_{2}$ and the relational property green for $S_{3}$ in $C_{3}$ - that the tomato is related to $S_{2}$ in $C_{2}$ and to $S_{3}$ in $C_{3}$ in the ways required of things that exemplify those two color properties. Indeed, it seems clear, we could continue this banal exercise forever. That is, there seem to exist infinitely many relational properties that relate things to (actual and possible) perceivers and (actual and possible) viewing conditions in the way we are imagining (viz., red for $S_{1}$ in $C_{1}$, blue for $S_{2}$ in $C_{2}$, green for $S_{3}$ in $C_{3}, \ldots$ ), and it seems that a ripe tomato will exemplify infinitely many of these relational properties.

I cannot discern any untoward ontological explosion in the case of the left hand - I see no reason that left hands can't exemplify infinitely many relational properties that relate them to numbers. Similarly, I see no reason that ripe tomatoes can't exemplify infinitely many relational properties that relate them to (actual and possible) perceivers and (actual and possible) viewing circumstances. What is good for a left hand is good enough for a ripe tomato.

\subsection{Relationalism and Looking Yellow}

A further cluster of ontological objections against relationalism builds on the idea that the expression 'looks' (when it appears in contexts like ' $x$ looks yellow') should be understood intentionally - that it should be understood in terms of the properties that are visually presented. Questions about the understanding of such attributions matter to the relationalist, since (i) she is prepared to appeal to such attributions as evidence for attributing colors to objects, and (ii) in particular, this sort of evidence plays a key role in the argument from perceptual variation offered in support of color relationalism (for example, two paradigmatic data are that a ripe lemon looks yellow to me in some visual circumstance - say, in the kitchen, and that the very same ripe lemon fails to look yellow to me in some other visual circumstance - say, in the basement). ${ }^{47}$

\footnotetext{
${ }^{47}$ N.B.: It should be clear that, as I am understanding it, relationalism does not require the identification of yellow for $S$ in $C$ with looks yellow for $S$ in $C$, although some particular forms of relationalism may end up endorsing the identification (see note 21). Obviously, relationalists who make the contemplated identification need an account of the latter property; but, for reasons given in the main text, other relationalists need such an account as well.
} 
Can the relationalist make sense of such attributions? Given an intentional understanding of 'looks', the claim that the lemon looks yellow to me in the kitchen must mean that the lemon is visually presented to me in the kitchen as having some property. But what property? For the relationalist, the property in question is not the non-relational property yellow, but a relational property such as yellow for $S$ in $C$. Thus, if we interpret 'looks' intentionally, the relationalist's crucial datum about the way the lemon looks to me in $C_{1}$ must be understood as saying that the lemon is visually presented to me in the kitchen as having the relational property yellow for $S$ in $C$. My question, in the rest of this section, will be whether this result is damaging to the relationalist. My answer will be that it is not.

The first point to make in this connection is that the intentional understanding of 'looks' locutions is (of course) a substantive theoretical assumption that a relationalist may be inclined to reject. Indeed, I have argued elsewhere for an alternative treatment of looks locutions (one that is possibly nonintentional, depending on further theoretical commitments) ([Cohen, 2003a], $\S 1.3$; see [Peacocke, 1984] for a more resolutely non-intentionalist proposal). If, as it seems to me, these views are live options, then the relationalist who adopts one of them can neatly sidestep the difficulties under discussion.

That said, I want to suggest that there is no difficulty here even for a relationalist who accepts an intentional understanding of 'the lemon looks yellow to $S$ in $C^{\prime}$, and hence is committed to understanding the latter as saying that the lemon is visually presented to me in the kitchen as having the relational property yellow for $S$ in $C$. To make this case, it will be helpful to consider the elements that show up in the analysis one at a time: first the notion of visual presentation, then the relational properties, and finally the variable letters invoked inside the relational properties.

First, consider the notion of visual presentation that shows up in the contemplated analysis. I take it that the explanation of this notion is incumbent on relationalists and non-relationalists alike, so not a special problem for relationalism.

Consider next that the analysis adverts to relational color properties (e.g., yellow for $S$ in $C$ ). Of course, these properties are also in need of explication. However, if relationalists owe an explication of these relational property, this is not a task from which any relationalist would shy away: what makes one a relationalist is just precisely that one is willing to defend an account of such properties. For example, dispositionalists propose a dispositional understanding of yellow for $S$ in $C$, functionalists propose a functional understanding of the same property, and so on (see note 1). ${ }^{48}$ Once again, this element of the analysis fails to expose an unmet explanatory burden for relationalists.

\footnotetext{
${ }^{48}$ That said, since my purpose in the present paper is to argue for relationalism per se, rather than for any particular species of that view, it would not serve my ecumenical aspirations if I were to plump for a particular metaphysical account of yellow for $S$ in $C$. As I see it, then, the present concern is best understood as laying down an explanatory requirement that particular forms of relationalism must meet, but not a requirement that a general defense of relationalism (such as the present paper) should meet.
} 
Finally, let us turn our attention to the question of just which relational properties should appear in the analysis of 'looks yellow to $S$ in $C$ '; in particular, how fine-grained are the specifications of values for $S$ and $C$ in the above schema? For example, should we say that the lemon looks yellow to me in the kitchen just in case the lemon is presented to me in the kitchen as having the relational property yellow for me in the kitchen? Or, following the suggestion of $\S 4$, should we say that the lemon looks yellow to me in the kitchen just in case the lemon is presented to me in the kitchen as having the relational property yellow for visual systems pretty much like my own in viewing circumstances pretty much like those I typically encounter? This, it seems to me, is a matter on which reasonable relationalists can disagree - it is one more parameter that distinguishes specific forms of relationalism. I conclude that the question under consideration is one that a specific relationalist view would answer, but I don't see any reason for thinking that doing so would present particular difficulties for relationalists.

As far as I can see, then, the relationalist about color has no difficulty in endorsing claims of the form 'the lemon looks yellow to me in the kitchen', whether or not she accepts an intentional understanding of 'looks' locutions. Of course, doing so may require that she offer more in explanation after she has articulated the more specific form that her relationalism will take. But that, it seems to me, is not a flaw of the view.

\section{Applications}

So far, I have adduced empirical motivations for a relational understanding of colors ( $\S 3)$, and defended that understanding from objections ( $\left.\S 4_{-5}-5\right)$. In addition, I believe that relationalism is superior to anti-relationalism because theories of the former (but not the latter) sort are able to solve certain otherwise threatening puzzles. I share Russell's view that theories should be adjudged (at least partly) on the basis of their capacity for dealing with puzzles ([Russell, 1905], 206), and therefore take relationalism's success at dispatching the puzzles of this section as an important point in its favor.

\subsection{Averill's Trilemma, Hilbert's Puzzle}

First, relationalism offers a uniform and attractively simple solution to a pair of related puzzles pressed in [Averill, 1985] and [Hilbert, 1987]. Averill and Hilbert both appeal to cases of perceptual variation, although they use them to motivate very different conclusions; what unites these two authors is that the puzzles they raise from such cases (and, therefore, the motivation for the conclusions they draw from the puzzles) dissolve immediately if relationalism is true.

\subsubsection{Averill's Trilemma}

Averill's version of the puzzle builds from the observation that "objects that reflect very different combinations of wavelengths of light can appear to be 
the same color to normal human beings looking at these objects in sunlight" ([Averill, 1985], 12). He then uses this fact to formulate a trilemma:

... suppose that the paints in two pots, $A$ and $B$, appear to normal humans to be the same shade of yellow in sunlight; and suppose that the paint in pot $A$ reflects only light from the red and green parts of the spectrum and the paint in pot $B$ reflects only light from the yellow and blue parts of the spectrum (the large majority of which will be light from the yellow part of spectrum). A figure is painted on a canvas with paint from pot $A$, and the background is filled in with paint from pot $B$. The canvas now appears to be a uniform shade of yellow to normal human beings looking at it in sunlight. What is the color of this canvas? Clearly the following three statements are inconsistent:

(a) The canvas is a uniform shade of yellow.

(b) This uniform shade of yellow is one distinct color.

(c) The figure on the canvas is different in color from its background.

... How should the trilemma be resolved? ([Averill, 1985], 12-13).

It should be clear that this trilemma revolves around a case of perceptual variation: the appearance of figure and background vary independently when subjected to different illumination, such that figure and background are indistinguishable (in respect of color) under sunlight illumination $I_{1}$, but distinguishable (in respect of color) under a different illuminant $I_{2}$ (without loss of generality, we may suppose this different illuminant is comprised of "only light from the red and green parts of the spectrum," so that the pot $A$ figure reflects some portion of the incident illumination but the pot $B$ ground does not). The appearance of the canvas under $I_{1}$, presumably, is what motivates premise (a), while the appearance of the canvas under $I_{2}$, presumably motivates premise (c). The putative inconsistency, of course, comes from the introduction of premise (b): if the uniform shade of yellow is "one distinct color," then it would seem that either that one distinct color is shared by figure and background, or that it is not. But saying that figure and ground are alike in color appears incompatible with premise (c), while saying that figure and ground are unlike in color appears incompatible with premise (a).

But the relationalist will insist that the appearance of inconsistency, and therefore the trilemma, depends on requiring a choice that we need not and should not make. In particular, she will point out, the difficulty disappears once we recognize the tacit references to visual systems and viewing conditions presupposed by ordinary color thought and talk. According to the relationalist, the indistiguishability of figure and background under illuminant $I_{1}$ justifies us in accepting (not premise (a), but)

$\left(\mathbf{a}^{\prime}\right)$ The figure and background of the canvas are uniform in color (i.e., they share a color): they both exemplify yellow for $S$ in $C_{1}$. 
Likewise, the distinguishability of the figure and background under $I_{2}$ motivates (not premise (c), but)

$\left(\mathbf{c}^{\prime}\right)$ The figure and background of the canvas are not uniform in color (they fail to share a color): the figure does, but the background does not, exemplify the color yellow for $S$ in $C_{2}$.

And now, of course, premise (b) is unproblematically compatible with both $\left(\mathrm{a}^{\prime}\right)$ and $\left(\mathrm{c}^{\prime}\right)$ - it says, correctly, that 'this uniform shade of yellow' (namely, I take it, the color that $\left(\mathrm{a}^{\prime}\right)$ ascribes) is one distinct color. Indeed, that color is one distinct color that the regions both exemplify, and both manifest, in $C_{1}$ (as per $\left.\left(a^{\prime}\right)\right)$. It is also true that there is some other color that they fail to share and that only one of them manifests in $C_{2}$ (as per $\left.\left(\mathrm{c}^{\prime}\right)\right)$.

If, as the relationalist maintains, color are constituted in terms of relations to (inter alia) viewing conditions, then this is just what we should expect: changing the viewing condition (by changing the illumination) changes the color that each region manifests, so that the two regions can manifest a shared color in one condition but not in another. The relationalist answer to the trilemma, then, is to say that its three premises are, once suitably marked with the needed and independently motivated relativizations (cf. $\S 3$ ), perfectly compatible. ${ }^{49}$

In contrast, this strategy of response to the trilemma is not available to an anti-relationalist. This strategy requires holding that $x$ and $y$ can simultaneously share one color property (yellow for $S$ in $C_{1}$ ) and fail to share another color property (yellow for $S$ in $C_{2}$ ). But, so long as the intrinsic makeups of $x$ and $y$ are held constant between $C_{1}$ and $C_{2}$ (as required by Averill's case), an anti-relationalist will not be able to secure this result, since, for her, the question whether $x$ and $y$ share a color property is answered determinately by whether $x$ and $y$ have a particular intrinsic property. On the other hand, [Averill, 1985] argues persuasively against resolutions of the trilemma that deny either (a) or (c), and accounts involving a repudiation of (b) (such as Averill's own proposal) seem to require the counterintuitive claim that things can be the same shade but be different colors.

Thus, an anti-relationalist response to the trilemma requires denying at least one of (a), (b), and (c), where each of these denials has serious prima facie costs. In contrast, the relationalist can answer the trilemma while accepting all of its component claims, once these have been modified to reflect the tacit relativizations she insists (on independent empirical grounds) they must hide. Accordingly, I prefer relationalism over anti-relationalism insofar as I prefer simple, independently motivated solutions over serious prima facie costs. ${ }^{50}$

\footnotetext{
${ }^{49}$ The relationalist can also explain why it might have erroneously seemed to some (e.g., to Averill) that there was an inconsistency. The relationalist allows that ordinary color discourse leaves the needed relativizations tacit (see $\$ 4$ ), but the solution on offer depends on their being made explicit. By leaving the relativizations tacit, Averill's formulation of the trilemma respects the surface form of ordinary color discourse too closely, and therefore obscures the availability of the relationalist solution.

${ }^{50}$ In [Averill, 1992], Averill uses the same sort of puzzle to motivate what he calls a "relational account of color." This account, which is related to my account of the same name,
} 


\subsubsection{Hilbert's Puzzle}

In [Hilbert, 1987], chapter 5, Hilbert uses a similar puzzle to argue for his antirelationalist account of color and against a relational (dispositional) account. ${ }^{51}$ Hilbert's version of the puzzle revolves around metamers - pairs of surfaces that have distinct surface spectral reflectance distributions, but that are perceptual matches for a given observer and a given viewing condition. Metamers have long been cited as an objection to the identification of colors with surface spectral reflectance distributions. Hilbert formulates the puzzle to respond to that objection, thereby defending the identification between colors and surface spectral reflectance distributions.

As Hilbert notes, members of a metameric pair that are perceptual matches (for an observer) under one illuminant $I_{1}$ must be perceptual mismatches (for that observer) under some different illuminant $I_{2} \cdot{ }^{52}$ Thus, he suggests, we are faced with a choice point: should we, or should we not, claim that the two surfaces are alike in color? We can insist (on the strength of their matching for some observer under $I_{1}$ ) that the metameric pair share a color, or we can say (on the strength of their not matching for the same observer under $I_{2}$ ) that the two fail to share a color. Hilbert thinks everyone needs to make this choice, and points out that either choice involves attributing an error to the individuations made by ordinary perception: if the two share a color, then the appearance in $I_{2}$ that they do not is erroneous, but if the two fail to share a color, then the appearance in $I_{1}$ that they do is erroneous. Given this set of alternatives, Hilbert claims, it is preferable to attribute the error to the appearance in $I_{1}$ : after all, if the appearance of difference in $I_{2}$ is an illusion, it is a case where an illusory apparent difference reveals an intrinsic difference between the surfaces — and that, claims Hilbert, sounds more like a veridical appearance than an illusion! Hence, for Hilbert, the case provides justification for the policy of making color distinctions between metameric surfaces, and thereby vindicates the identification of colors with surface spectral reflectances.

But, from the relationalist perspective, it seems that Hilbert's puzzle errs

resolves these puzzles along the lines that I am proposing. That said, Averill's relationalism differs from mine in several respects; perhaps the most important of these is that Averill considers fewer sources of perceptual variation than I have discussed in $\S 3$, and consequently relativizes colors to far fewer parameters than I have argued is necessary. Second, Averill is much more confident than I am in the possibility of a non-stipulative account of 'normal observer' and 'optimal viewing conditions' ([Averill, 1992], 557-558), hence in ruling out difficult cases (such as rainbows) as color illusions. And third, Averill gives no account of the relation between colors, construed as relational properties, and our ordinary, apparently unrelativized color attributions (as I have in $\S 4$ ).

${ }^{51}$ It is worth noting that Hilbert's account is in fact relational along the single dimension of viewing distance: the surface spectral reflectance distributions he identifies with colors are relativized to viewing distance, as emphasized in chapter 2 of [Hilbert, 1987]. Nonetheless, I count this view as an anti-relationalist account since it takes colors to be non-relational, and not relativized to visual systems or any of the other parameters discussed in $\S 3$. See note 8 .

${ }^{52}$ The members of a metameric pair can be perceptual matches under all illuminants only if they have the same spectral reflectance distribution, in which case they are called isomers; but isomers are identified in color by both Hilbert's theory and ordinary perception, so they are not challenges to the individuations made the theory. 
in just the place that Averill's trilemma goes wrong: both cases present a choice between two conflicting judgments (made in different circumstances) about whether a certain pair of surfaces share a color, and then forces us to choose between those judgments. As I have argued, this is a choice that we ought refuse to make. ${ }^{53}$ As in the case of Averill's trilemma, it is a mistake to choose between holding that the surfaces always share a color (because they are a perceptual match in $I_{1}$ ) and holding that they never share a color (because they are not a perceptual match in $I_{2}$ ). Instead, we should hold that both (i) that the surfaces share a color in $I_{1}$ and (ii) the surfaces fail to share a color in $I_{2}$. In this way, we can respect both of the intuitions whose rejection strikes us as unpalatable. One again, relationalism provides a simple and well-motivated alternative to a forced choice between unpalatable alternatives. ${ }^{54}$

\subsection{Homogeneity}

A further benefit of a relational view of color is that it sustains and clarifies a widely held intuition concerning the homogeneity of colors.

The homogeneity intuition builds on the idea that colors are homogeneous throughout their spatial extent. This intuition is nicely expressed by Sellars in this famous passage:

... there is no trouble about systems having properties which its [sic] parts do not have if these properties are a matter of the parts having

\footnotetext{
${ }^{53}$ In fairness, I should note that Hilbert briefly considers the option of endorsing both judgments, as I am suggesting, but rejects it on the strength of an objection I've already considered. Namely, he alleges that relationalism is unacceptably revisionary because it makes no room for erroneous color attributions:

We commonly take colors to be relatively stable properties of objects. In particular, we take the color of an object to be independent of the illumination under which it is viewed. Colors in our common sense ontology are illuminationindependent properties of objects. The stability of colors and in particular their illumination independence is reflected in the distinction between real and apparent colors. [On the option considered] there is no distinction between real and apparent colors. The apparent color at any given time is the real color of the object at that time ([Hilbert, 1987], 88).
}

However, as I argued in $\S 4$, the relationalist can account for the intuitions of illuminationindependence and the distinction between real and apparent color that Hilbert adduces. Namely, she can explain these as intuitions about ordinary color ascriptions — viz., as intuitions about the colors things have, given the tacitly presupposed relativizations at work in ordinary thought and talk about color.

54 As explained in the main text, I think the most serious problem with the argument under consideration is its insistence on choosing between (what even Hilbert would regard as) prima facie unattractive options; I've been urging throughout the present paper that one should respond to such hard choices by refusing to choose. However, putting this point aside and spotting the assumption that we must choose, it seems to me that the grounds Hilbert proffers for making the choice beg the disputed question. He proposes to side with one of the apparently conflicting perceptual judgments at the expense of the other on the grounds that one of them fits better with the intrinsic difference in spectral reflectance distributions of the two surfaces. But it is unclear why our color attributions should respect this difference in intrinsic properties unless we are already assuming that colors are intrinsic properties, and thereby begging the question against the relationalist. 
such and such qualities and being related in such and such ways. But the case of a pink ice cube, it would seem clear, cannot be treated in this way. It does not seem plausible to say that for a system of particles to be a pink ice cube is for them to have such and such imperceptible qualities, and to be so related to one another as to make up an approximate cube. Pink does not seem to be made up of imperceptible qualities in the way in which being a ladder is made up of being cylindrical (the rungs), rectangular (the frame), wooden, etc. The manifest ice cube presents itself to us as something which is pink through and through, as a pink continuum, all the regions of which, however small, are pink. It presents itself to us as ultimately homogeneous... ([Sellars, 1963], 26, emphasis in original).

Initially, we might attempt to represent the Sellarsian intuition as follows:

$\left(\mathbf{H}_{1}\right)$ If $x$ is pink, then every proper part of $x$ is pink (mutatis mutandis for the other colors).

However, $\left(\mathrm{H}_{1}\right)$ must be modified: as Berkeley (Three Dialogues between Hylas and Philonous, First Dialogue) and Locke (Essay Concerning Human Understanding, II.xxiii.11) both point out, microscopes show us that blood, which appears red when seen with the naked eye, contains proper parts that are colorless (cf. [Russell, 1912], 10). One might plausibly respond to this observation by pointing out that, while there are proper parts of (red) blood that are not red, these parts are not visible in the circumstances under which blood is ordinarily observed, and under which the color red is ascribed to it. On the other hand, one might think, the intuition that $\left(\mathrm{H}_{1}\right)$ attempts to express is that only parts visible in the same circumstance in which the whole is visible must share a color with the whole. Perhaps, then, the way to assimilate the lesson of the microscope is to replace $\left(\mathrm{H}_{1}\right)$ with a suitably restricted formulation, containing explicit relativizations to reflect points made above; thus,

$\left(\mathbf{H}_{2}\right)$ if $x$ is pink for $S$ in $C$, then every proper part of $x$ that is visible to $S$ in $C$ is pink for $S$ in $C$ (mutatis mutandis for the other colors).

I take intuitions about the homogeneity of color to be important, and therefore worth capturing. For one thing, whether or not Sellars's reflections are convincing by themselves, it is hard to see why the observation of colorless parts of blood under a microscope would have been surprising (which it undoubtedly was) were not some such intuitions in place. However, there are cases, related to some we have already considered in the course of arguing for relationalism, that might seem to raise trouble for the homogeneity intuition (understood as $\left(\mathrm{H}_{2}\right)$ ). My contention will be that relationalism contains the resources to respond to such cases in a way that preserves and clarifies the homogeneity intuition.

The initially problematic case I have in mind is based on the general principle underlying contrast effects (see §3.3). Consider square $R$, which is pink for $S$ in $C$ (see figure 6a). Suppose that $R$ is composed (exhaustively) of two subregions $R^{*}$ and $R^{\prime}$ (figure $6 \mathrm{~b}-6 \mathrm{~d}$ ). Now suppose we separately attend to subregions $R^{*}$ 
Figure 5: (a) Square $R$. (b) Subregion $R^{*}\left(\subseteq R\right.$ ). (c) Subregion $R^{\prime}(\subseteq R)$, such that $R^{\prime} \cap R^{*}=\{\}$. (d) $R=R^{*} \cup R^{\prime}$.

and $R^{\prime}$ in turn. When we attend to $R^{*}$ on its own - without attending to its complement in $R$ (viz., $R^{\prime}$ ), it remains pink (figure 6b). In contrast, when we attend to $R^{\prime}$ on its own - without attending to its complement in $R$ (viz., $R^{*}$ ), it ceases to be pink (figure 6c). ${ }^{55}$ That is, the color of $R^{\prime}$ depends systematically on whether it is being viewed together with $R^{*}$ (figure 6a) - in which case it is (stably) pink - or on its own (figure 6c) - in which case it is (stably) not pink. Finally, when we turn our visual attention to all of $R$ once again (figure $6 \mathrm{~d}$ ), both components $R^{*}$ and $R^{\prime}$ are pink. If such a case is possible, it might seem a threat to $\left(\mathrm{H}_{2}\right): R^{\prime}$ is a proper part of $R$ that is visible in the same circumstance in which $R$ is visible (and to the same subject), but (at least sometimes) $R^{\prime}$ fails to share the color pink with $R .{ }^{56}$

Should we, on the basis of such cases, jettison the initially plausible principle $\left(\mathrm{H}_{2}\right)$ ? We should not. For, I shall contend, the resources relationalism makes available permit us to describe the case in a way that is compatible with $\left(\mathrm{H}_{2}\right)$.

Consider $R$ again. When we attend to $R$, ordinarily we are also attending to $R^{\prime}$, which is, after all, one of $R$ 's proper parts. ${ }^{57}$ To say this is to say that there is some viewing condition in which we are attending to both $R$ and $R^{\prime}$; call this condition $C_{1}$. Now consider the situation in which we attend to $R^{\prime}$ without the rest of $R$, viz., one in which we attend to $R^{\prime}$ without attending to $R^{*}$; call this condition $C_{2}$. Clearly $C_{1}$ and $C_{2}$ are not identical, since $C_{1}$ but not $C_{2}$ is a condition under which we attend to $R$. Therefore, given a relationalist understanding of colors, it is open to us to suppose that $R^{\prime}$ could exemplify a

\footnotetext{
${ }^{55}$ We may suppose, for the sake of concreteness, that it becomes clear; all that matters for the point of the case is that it ceases to be pink.

${ }^{56}$ Presumably one could raise largely the same puzzle by appeal to the homogeneity of colored regions with respect to their temporal parts instead of their spatial parts. I'll put this complication aside in what follows, since it seems to me that the temporal version adds nothing substantially different.

${ }^{57}$ One may wish to claim that there is some sort of in-virtue-of relation at work here that we always attend to a region in virtue of attending to its proper parts. But I don't want or need to hold my contention hostage to a substantive metaphysical claim of this generality; all I need for present purposes is that, in at least many typical cases, it is true that we attend (at a given time) to both a region and one of its proper parts.
} 
certain color for $S$ in $C_{1}$ and fail to exemplify that color for $S$ in $C_{2} \cdot{ }^{58}$

I propose to describe the case by saying that $R^{\prime}$ exemplifies pink for $S$ in $C_{1}$, but that it fails to exemplify pink for $S$ in $C_{2}{ }^{59}$ Of course, $R$ and $R^{*}$ have the property pink for $S$ in $C_{1}$ as well. Thus, one of $R$ 's color properties distributes over its proper parts $R^{*}$ and $R^{\prime}$, as demanded by $\left(\mathrm{H}_{2}\right)$. What about the property pink for $S$ in $C_{2}$ ? Neither $R$ nor $R^{*}$ is visible in $C_{2}-$ neither of them looks any way at all in $C_{2}$, so neither of them has any color that is relativized to $C_{2}$ (although they both have in $C_{2}$ colors that are relativized to $C_{1}$ ). And the setup of the case ensures that $R^{\prime}$ fails to exemplify pink for $S$ in $C_{2}$. Consequently, the other of $R$ 's color properties under discussion distributes over its proper parts $R^{*}$ and $R^{\prime}$; once again, $\left(\mathrm{H}_{2}\right)$ is respected.

This description, I suggest, not only preserves $\left(\mathrm{H}_{2}\right)$ against the case under consideration, but also sheds light on $\left(\mathrm{H}_{2}\right)$ itself and the conclusions it licenses and does not license. $\left(\mathrm{H}_{2}\right)$ is true, but we must remember that our specifications of the viewing conditions must take account of other things we are viewing simultaneously - a conclusion we had already reached on independent (empirical) grounds in $\S 3$. $\left(\mathrm{H}_{2}\right)$ tells us that if $x$ is pink for $S$ in $C$, then every proper part of $x$ that is visible for $S$ in $C$ is pink for $S$ in $C$. This licenses us in concluding, from the fact that $R$ is pink for $S$ in $C_{1}$, that $R^{\prime}$ is pink for $S$ in $C_{1}$. What this does not license is the conclusion that $R^{\prime}$ is pink for $S$ in $C_{2}$, or in any other arbitrary circumstance.

Relationalism, then, provides a description of the case that respects intuitions about homogeneity, and also has lessons to teach about the way in which such intuitions should be understood. I count these as further benefits for the view.

\section{Conclusion}

I have argued for a relational understanding of color properties - an understanding that takes colors to be constituted in terms of relations between objects, viewers, and viewing conditions. I believe that relational views accommodate the relevant empirical data better than anti-relational views (§3), make available a plausible and well-motivated account of the relation between colors and

\footnotetext{
${ }^{58}$ Objection: the relationality here seems ad hoc: there is no principled a priori reason to think that the present difference between $C_{1}$ and $C_{2}$ reflects a variation in any parameter of a relation in terms of which colors are constituted.

Response: The suggestion should be assessed on the same principled, broadly empirical grounds employed regarding other parameters throughout $\S 2$. Colors should be construed as involving a relation to a parameter just in case, with all other factors fixed, a change in the relevant parameter can produce a difference in the colors things look to have to a given visual system (and there is no well-motivated, theory-independent reason for setting aside changes in that parameter; cf. note 41). If the case under discussion is possible, the presence of $R^{*}$ contiguous to $R^{\prime}$ is just the sort of difference that makes a difference to how things look to $S$.

${ }^{59}$ When viewed in $C_{2}$, does $R^{\prime}$ exemplify pink for $S$ in $C_{1}$ ? Yes, it does; but, while it is in $C_{2}$ rather than $C_{1}$, it does not manifest this property; instead, while in $C_{2}, R^{\prime}$ manifests a color property that is relativized to $C_{2}$. Consequently, as we move between the two viewing conditions, we do not destroy and reconstitute this color of $R^{\prime}$, but merely make it manifest or not manifest.
} 
ordinary color discourse $(\S 4)$, that they withstand the philosophical objections they face $(\S \S 4-5)$, and that they resolve several puzzles about color that have figured in the literature $(\S 6)$.

While relationalism leaves room for disagreement about the metaphysics of color, it puts substantive constraints on the kind of color ontology we should accept. That, it seems to me, is progress. ${ }^{60}$

\section{References}

[Albers, 1963] Albers, J. (1963). Interaction of Color. Yale University Press, London.

[American Society for Testing and Materials, 1968] American Society for Testing and Materials (1968). Standard Method of Specifying Color by the Munsell System. ASTM, Philadelphia. Designation D 1535-68.

[Arend and Reeves, 1986] Arend, L. and Reeves, A. (1986). Simultaneous color constancy. Journal of the Optical Society of America A, 3(10):1743-1751.

[Arend et al., 1991] Arend, L., Reeves, A., Schirillo, J., and Goldstein, R. (1991). Simultaneous color constancy: patterns with diverse Munsell values. Journal of the Optical Society of America A, 8:661-672.

[Armstrong, 1968] Armstrong, D. (1968). A Materialist Theory of the Mind. Routledge, London.

[Averill, 1985] Averill, E. W. (1985). Color and the anthropocentric problem. The Journal of Philosophy, 82:281-304. Reprinted in [Byrne and Hilbert, 1997b], 11-32.

[Averill, 1992] Averill, E. W. (1992). The relational nature of color. The Philosophical Review, 101(3):551-588.

[Bäuml, 1999] Bäuml, K.-H. (1999). Simultaneous colour constancy: how surface color perception varies with the illuminant. Vision Research, 39(8):15311550 .

[Bennett, 1968] Bennett, J. (1968). Substance, reality, and primary qualities. In Martin, C. B. and Armstrong, D. M., editors, Locke and Berkeley: A Collection of Critical Essays, pages 86-124. Anchor Books, Garden City, New York.

[Bennett, 1971] Bennett, J. (1971). Locke, Berkeley, Hume: Central Themes. Clarendon Press, Oxford.

\footnotetext{
${ }^{60}$ I am grateful to Ed Averill, Alex Byrne, Craig Callender, Jerry Fodor, Rick Grush, Larry Hardin, David Hilbert, Don MacLeod, Mohan Matthen, Brian McLaughlin, Ram Neta, Shaun Nichols, Sam Rickless, Sydney Shoemaker, and two anonymous referees for this journal for their valuable advice concerning the present paper.
} 
[Bowmaker and Dartnall, 1980] Bowmaker, J. and Dartnall, H. (1980). Visual pigments of rods and cones in a human retina. Journal Physiologica, 298:501511.

[Boynton, 1979] Boynton, R. M. (1979). Human Color Vision. Holt, Rinehart and Winston, New York.

[Byrne and Hilbert, 1997a] Byrne, A. and Hilbert, D. R. (1997a). Colors and reflectances. In Byrne, A. and Hilbert, D. R., editors, Readings on Color, Volume 1: The Philosophy of Color, pages 263-288. MIT Press, Cambridge, Massachusetts.

[Byrne and Hilbert, 1997b] Byrne, A. and Hilbert, D. R., editors (1997b). Readings on Color, Volume 1: The Philosophy of Color. MIT Press, Cambridge, Massachusetts.

[Byrne and Hilbert, 1997c] Byrne, A. and Hilbert, D. R. (1997c). Readings on Color, Volume 2: The Science of Color. MIT Press, Cambridge, Massachusetts.

[Byrne and Hilbert, 2003] Byrne, A. and Hilbert, D. R. (2003). Color realism and color science. Behavioral and Brain Sciences, 26(1):3-64.

[Cicerone and Nerger, 1989] Cicerone, C. M. and Nerger, J. L. (1989). The relative number of long-wavelength-sensitive to middle-wavelength-sensitive cones in the human fovea. Vision Research, 26:115-128.

[Clark, 1993] Clark, A. (1993). Sensory Qualities. Clarendon Press, Oxford.

[Cohen, 2003a] Cohen, J. (2003a). Color: A functionalist proposal. Philosophical Studies, 112(3):1-42.

[Cohen, 2003b] Cohen, J. (2003b). Color constancy as counterfactual. Under review.

[Cohen, 2004] Cohen, J. (2004). Color, variation, and the appeal to essences: Impasse and resolution. Under review.

[Cohen and Meskin, 2004] Cohen, J. and Meskin, A. (2004). On the epistemic value of photographs. Journal of Aesthetics and Art Criticism, 62(2):197-210.

[Cornelissen and Brenner, 1995] Cornelissen, F. W. and Brenner, E. (1995). Simultaneous colour constancy revisited: an analysis of viewing strategies. $V i$ sion Research, 35:2431-2448.

[Cronin and Marshall, 1989] Cronin, T. W. and Marshall, N. J. (1989). A retina with at least ten spectral types of photoreceptors in a mantis shrimp. Nature, 339:137-140. 
[Dartnall et al., 1983] Dartnall, H., Bowmaker, J. K., and Mollon, J. D. (1983). Human visual pigments: microspectrophotometric results from the eyes of seven persons. Proceedings of the Royal Society of London B, 220:115-130.

[Evans, 1948] Evans, R. M. (1948). An Introduction to Color. Wiley, New York.

[Hagstrom et al., 1998] Hagstrom, S., Neitz, J., and Neitz, M. (1998). Variation in cone populations for red-green color vision exampled by analysis of mRNA. NeuroReport, 9:1963-1967.

[Hardin, 1988] Hardin, C. L. (1988). Color for Philosophers: Unweaving the Rainbow. Hackett, Indianapolis.

[Harman, 1996] Harman, G. (1996). Explaining objective color in terms of subjective reactions. In Villanueva, E., editor, Philosophical Issues, volume 7. Ridgeview, Atascadero, California. Reprinted in [Byrne and Hilbert, 1997b], 247-261.

[Hilbert, 1992] Hilbert, D. (1992). Comparitive color vision and the objectivity of color: Open peer commentary on [Thompson et al., 1992]. Behavioral and Brain Sciences, 15:38-39.

[Hilbert, 1987] Hilbert, D. R. (1987). Color and Color Perception: A Study in Anthropocentric Realism. CSLI, Stanford.

[Hull, 1978] Hull, D. (1978). A matter of individuality. Philosophy of Science, 45:335-360.

[Humberstone, 1996] Humberstone, L. (1996). Intrinsic/extrinsic. Synthese, 108(2):205-267.

[Humphreys, 1964] Humphreys, W. J. (1964). Physics of the Air. Dover, New York.

[Hurvich, 1981] Hurvich, L. M. (1981). Color Vision. Sinauer Associates, Sunderland, Massachusetts.

[Jackson, 1996] Jackson, F. (1996). The primary quality view of color. Philosophical Perspectives, 10:199-219.

[Jackson, 1998] Jackson, F. (1998). From Metaphysics to Ethics: A Defence of Conceptual Analysis. Oxford, New York. Originally given as the 1998 Locke Lectures.

[Jackson and Pargetter, 1987] Jackson, F. and Pargetter, R. (1987). An objectivist's guide to subjectivism about color. Revue Internationale de Philosophie, 160:127-141. Reprinted in [Byrne and Hilbert, 1997b], 67-79.

[Jacobs and Deegan, 1997] Jacobs, G. H. and Deegan, J. F. (1997). Spectral sensitiviy of macaque monkeys measured with ERG flicker photometry. Visual Neuroscience, 14:921-928. 
[Jacobs and Neitz, 1993] Jacobs, G. H. and Neitz, J. (1993). Electrophysiological estimates of individual variation in the $\mathrm{L} / \mathrm{M}$ cone ratio. In Drum, B., editor, Colour Vision Deficiencies, volume XI of Documenta Opthalmologica Proceedings Series 56, chapter 11, pages 107-112. Kluwer Academic Publishers, Dordrecht.

[Jakab and McLaughlin, 2003] Jakab, Z. and McLaughlin, B. (2003). Why not color physicalism without color absolutism? Behavorial and Brain Sciences, 26(1):34-35.

[Jameson and Hurvich, 1978] Jameson, D. and Hurvich, L. M. (1978). Dichromatic color language: 'reds' and 'greens' don't look alike but their colors do. Sensory Processes, 2:146-155.

[Johnston, 1992] Johnston, M. (1992). How to speak of the colors. Philosophical Studies, 68:221-263. Reprinted in [Byrne and Hilbert, 1997b], 137-176.

[Judd and Wyszecki, 1963] Judd, D. B. and Wyszecki, G. (1963). Color in Business, Science, and Industry, Second Edition. Wiley, New York.

[Kelly and Judd, 1976] Kelly, K. L. and Judd, D. B. (1976). Color: Universal Language and Dictionary of Names. National Bureau of Standards, Washington, DC. Special Publication 440.

[Langton and Lewis, 1998] Langton, R. and Lewis, D. (1998). Defining 'intrinsic'. Philosophy and Phenomenological Research, 58(2):333-345.

[Lewis, 1997] Lewis, D. (1997). Naming the colors. Australasian Journal of Philosophy, 75(3):325-342.

[MacAdam, 1997] MacAdam, D. L. (1997). The physical basis of color specification. In Byrne, A. and Hilbert, D., editors, Readings on Color, Volume 2: The Science of Color, pages 33-63. MIT Press, Cambridge, Massachusetts.

[Martinich, 1990] Martinich, A. P. (1990). The Philosophy of Language, second edition. Oxford University Press, New York.

[Matthen, 1999] Matthen, M. (1999). The disunity of color. The Philosophical Review, 108(1):47-84.

[Matthen, 2001] Matthen, M. (2001). Our knowledge of colour. In Macintosh, J., editor, Naturalism, Evolution, and Intentionality, volume Supplementary volume 27, pages 215-246. Canadian Journal of Philosophy.

[Mayr, 1963] Mayr, E. (1963). Animal Species and Evolution. Harvard University Press, Cambridge, Massachusetts.

[McGinn, 1983] McGinn, C. (1983). The Subjective View: Secondary Qualities and Indexical Thoughts. Oxford University Press, Oxford. 
[McGinn, 1996] McGinn, C. (1996). Another look at color. The Journal of Philosophy, 93(11):537-553.

[McLaughlin, 1997] McLaughlin, B. (1997). Supervenience, vagueness, and determination. In Tomberlin, J. E., editor, Philosophical Perspectives 11: Mind, Causation, and World, pages 209-230. Ridgeview Publishing, Atascadero, California.

[McLaughlin, 2003] McLaughlin, B. (2003). The place of color in nature. In Mausfeld, R. and Heyer, D., editors, Colour Perception: Mind and the Physical World. Oxford University Press, New York.

[Munsell, 1946] Munsell, A. H. (1946). A Color Notation. Munsell Color, Baltimore.

[Munsell Color Company, 1976] Munsell Color Company (1976). Munsell Book of Color. Munsell Color, Baltimore.

[Peacocke, 1984] Peacocke, C. (1984). Colour concepts and colour experiences. Synthese, 58(3):365-81. Reprinted in [Rosenthal, 1991], 408-16.

[Pokorny et al., 1991] Pokorny, J., Smith, V. C., and Wesner, M. (1991). Variability in cone populations and implications. In Valberg, A. and Lee, B. B., editors, From Pigments to Perception, pages 23-34. Plenum, New York.

[Rickless, 1997] Rickless, S. C. (1997). Locke on primary and secondary qualities. Pacific Philosophial Quarterly, 78:297-319.

[Roorda and Williams, 1999] Roorda, A. and Williams, D. R. (1999). The arrangement of the three cone classes in he living human eye. Nature, 397:520522 .

[Rosenthal, 1991] Rosenthal, D. (1991). The Nature of Mind. Oxford University Press, New York.

[Ross, 1999] Ross, P. W. (1999). The appearance and nature of color. The Southern Journal of Philosophy, 37:227-252.

[Rossotti, 1983] Rossotti, H. (1983). Color: Why the World Isn't Grey. Princeton University Press, Princeton.

[Rushton and Baker, 1964] Rushton, W. A. H. and Baker, H. D. (1964). Red/green sensitivity in normal vision. Vision Research, 4:75-85.

[Russell, 1905] Russell, B. (1905). On denoting. Mind, 14:479-493. Reprinted in [Martinich, 1990], 203-211.

[Russell, 1912] Russell, B. (1912). The Problems of Philosophy. Oxford University Press, London. 
[Sacks, 1996] Sacks, O. (1996). The Island of the Colorblind. Vintage Books, New York.

[Sellars, 1963] Sellars, W. (1963). Philosophy and the scientific image of man. In Sellars, W., editor, Science, Perception and Reality, pages 1-40. Routledge and Kegan Paul, London.

[Shepard, 1992] Shepard, R. N. (1992). The perceptual organization of colors: An adaptation to regularities of the terrestrial world? In Barkow, J., Cosmides, L., and Tooby, J., editors, The Adapted Mind: Evolutionary Psychology and the Generation of Culture, pages 495-532. Oxford University Press, Oxford. Reprinted in [Byrne and Hilbert, 1997c], 311-356.

[Shoemaker, 1994a] Shoemaker, S. (1994a). Phenomenal character. Noûs, 28:21-38. Reprinted in [Byrne and Hilbert, 1997b], 227-245.

[Shoemaker, 1994b] Shoemaker, S. (1994b). Self knowledge and 'inner sense'. Philosophy and Phenomenological Research, 54:249-314. Reprinted in [Shoemaker, 1996], 201-268.

[Shoemaker, 1996] Shoemaker, S., editor (1996). The First-Person Perspective and Other Esays. Cambridge University Press, Cambridge.

[Shoemaker, 2000a] Shoemaker, S. (2000a). Introspection and phenomenal character. Philosophical Topics, 28(2):247-273.

[Shoemaker, 2000b] Shoemaker, S. (2000b). Phenomenal character revisited. Philosophy and Phenomenological Research, LX(2):465-468.

[Sober, 1984] Sober, E. (1984). Sets, species, and natural kinds - a reply to Philip Kitcher's "Species". Philosophy of Science, 51:334-341.

[Spackman, 2002] Spackman, J. (2002). Color, relativism, and realism. Philosophical Studies, 108:249-287.

[Stroud, 2000] Stroud, B. (2000). The Quest for Reality: Subjectivism and the Metaphysics of Colour. Oxford University Press, New York.

[Thau, 2002] Thau, M. (2002). Consciousness and Cognition. Oxford University Press, New York.

[Thompson, 1995] Thompson, E. (1995). Colour Vision: A Study in Cognitive Science and the Philosophy of Perception. Routledge, New York.

[Thompson et al., 1992] Thompson, E., Palacios, A., and Varela, F. (1992). Ways of coloring: Comparative color vision as a case study for cognitive science. Behavioral and Brain Sciences, 15:1-74.

[Troost and deWeert, 1991] Troost, J. M. and deWeert, C. M. M. (1991). Naming versus matching in color constancy. Perception $\& 3$ Psychophysics, 50:591602 . 
[Tye, 2000] Tye, M. (2000). Consciousness, Color, and Content. MIT Press, Cambridge, Massachusetts.

[Vimal et al., 1989] Vimal, R. L. P., Pokorny, J., Smith, V. C., and Shevell, S. K. (1989). Foveal cone thresholds. Vision Research, 29:61-78.

[Walton, 1984] Walton, K. (1984). Transparent pictures: On the nature of photographic realism. Critical Inquiry, 11:246-276.

[Werner, 1998] Werner, J. S. (1998). Aging through the eyes of Monet. In Backhaus, W. G. K., Gliegl, R., and Werner, J. S., editors, Color Vision: Perspectives From Different Disciplines, pages 3-41. Walter de Gruyter, Berlin.

[Wright, 1992] Wright, C. (1992). Truth and Objectivity. Harvard University Press, Cambridge, Massachusetts.

[Wyszecki and Stiles, 1967] Wyszecki, G. and Stiles, W. S. (1967). Color Science: Concepts and Methods, Quantitative Data and Formulae. Wiley, New York.

[Yablo, 1999] Yablo, S. (1999). Intrinsicness. Philosophical Topics, 26(1/2):479505.

[Yamaguchi et al., 1998] Yamaguchi, T., Motulsky, A. G., and Deeb, S. (1998). Visual pigment gene structure and expression in human retinae. Human Molecular Genetics, 6:981-990. 